

\section{Global report on PSORIASIS}

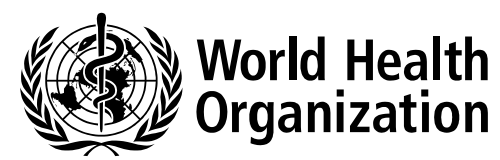


WHO Library Cataloguing-in-Publication Data

Global report on psoriasis.

1.Psoriasis - epidemiology. 2.Psoriasis - prevention and control. 3.Public Health. 4.Skin Diseases.

I.World Health Organization.

ISBN 9789241565189

(NLM classification: WR 205)

\section{๑) World Health Organization 2016}

All rights reserved. Publications of the World Health Organization are available on the WHO website (www.who. int) or can be purchased from WHO Press, World Health Organization, 20 Avenue Appia, 1211 Geneva 27, Switzerland (tel.: +41 22791 3264; fax: +41 22791 4857; e-mail: bookorders@who.int).

Requests for permission to reproduce or translate WHO publications - whether for sale or for non-commercial distribution- should be addressed to WHO Press through the WHO website (www.who.int/about/licensing/ copyright_form/en/index.html).

The designations employed and the presentation of the material in this publication do not imply the expression of any opinion whatsoever on the part of the World Health Organization concerning the legal status of any country, territory, city or area or of its authorities, or concerning the delimitation of its frontiers or boundaries. Dotted and dashed lines on maps represent approximate border lines for which there may not yet be full agreement.

The mention of specific companies or of certain manufacturers' products does not imply that they are endorsed or recommended by the World Health Organization in preference to others of a similar nature that are not mentioned. Errors and omissions excepted, the names of proprietary products are distinguished by initial capital letters.

All reasonable precautions have been taken by the World Health Organization to verify the information contained in this publication. However, the published material is being distributed without warranty of any kind, either expressed or implied. The responsibility for the interpretation and use of the material lies with the reader. In no event shall the World Health Organization be liable for damages arising from its use.

Printed in Switzerland.

\section{Cover by WHO/Graphics}

Design and layout: Jean-Claude Fattier 


\section{Contents}

Foreword —_ 1

Acknowledgements _ 2

Acronyms and abbreviations _ 3

List of figures, tables and boxes _ 4

Chapter 1. Introduction

What is psoriasis?

Why a global report on psoriasis? $\quad 6$

$\begin{array}{ll}\text { Chapter 2. The burden of psoriasis } & 7\end{array}$

$\begin{array}{ll}\text { Incidence and prevalence } & 7\end{array}$

$\begin{array}{ll}\text { Is psoriasis becoming more or less common? } & 10\end{array}$

$\begin{array}{lr}\text { Global disability burden from psoriasis } & 10\end{array}$

$\begin{array}{ll}\text { Gaps in data } & 12\end{array}$

Chapter 3. How does psoriasis affect peoples' lives? _ـ 13

$\begin{array}{lr}\text { Introduction } & 13\end{array}$

Skin and nails $\quad 13$

$\begin{array}{ll}\text { Psoriatic arthritis } & 15\end{array}$

$\begin{array}{ll}\text { Associated diseases } & 16\end{array}$

$\begin{array}{ll}\text { Psychological and mental health } & 16\end{array}$

$\begin{array}{ll}\text { Influences from the workplace } & 17\end{array}$

$\begin{array}{ll}\text { Social participation } & 17\end{array}$

$\begin{array}{ll}\text { Socioeconomic burden } & 17\end{array}$

$\begin{array}{ll}\text { Measuring the impact of psoriasis on quality of life } & 18\end{array}$

Chapter 4. Improving the quality of care for people with psoriasis _ 21

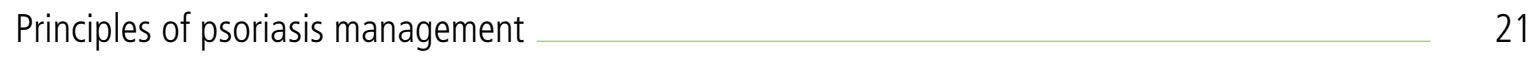


Treating the skin manifestations

Treating the whole person: beyond the skin manifestations

Understanding triggers

Barriers to quality care

What can be done?

Chapter 5. Recommendations

Actions for governments and policy-makers

Actions for health systems and health professionals

Actions for patients' organizations and civil society 34

Priority areas for research

References 


\section{List of figures, tables and boxes}

\section{List of figures}

Figure 1. Synopsis on psoriasis as a chronic disease with a high comorbidity

Figure 2. Prevalence of psoriasis by sex (year of data survey given; not of publication)

Figure 3. World map showing the DALYs for psoriasis per 100 000, rates for all ages and both sexes 11

Figure 4. Distribution of DALYs for psoriasis per 100000 , by gender and age group

Figure 5. Nail psoriasis

Figure 6. Psoriasis arthritis

Figure 7. Psoriasis management algorithm

Figure 8. Importance of patient needs related to treatment of psoriasis

\section{List of tables}

Table 1. Summary of studies on the prevalence of psoriasis

Table 2. Common types of psoriasis and their manifestations

Table 3. Treatment options for psoriasis

Table 4. Psoriasis treatment options included on the WHO Model List of Essential Medicines

\section{List of boxes}

Box 1. Model for improving psoriasis care on a national basis: the German experience

Box 2. Campaign "Focus on me, not my skin"

Box 3. Campaign "Swim for psoriasis" 


\section{Foreword}

Psoriasis is a common, chronic, noncommunicable skin disease, with no clear cause or cure. The negative impact of this condition on people's lives can be immense. Psoriasis affects people of all ages, and in all countries. The reported prevalence of psoriasis in countries ranges between $0.09 \%$ and $11.43 \%$, making psoriasis a serious global problem with at least 100 million individuals affected worldwide. Psoriasis has an unpredictable course of symptoms, a number of external triggers and significant comorbidities, including arthritis, cardiovascular diseases, metabolic syndrome, inflammatory bowel disease and depression.

In 2014, Member States recognized psoriasis as a serious noncommunicable disease (NCD) in the World Health Assembly resolution WHA67.9. The resolution highlighted that many people in the world suffer needlessly from psoriasis due to incorrect or delayed diagnosis, inadequate treatment options and insufficient access to care, and because of social stigmatization.

This WHO Global report on psoriasis brings the public health impact of psoriasis into focus. The report is written to help raise awareness of the range of ways that psoriasis can affect peoples' lives. It intends to empower policy-makers with practical solutions to improve the health care and social inclusion of people living with psoriasis in their populations.

The report highlights that much of the suffering caused by this common and complex disease can be avoided. Improving access to early diagnosis and appropriate treatment for psoriasis requires universally accessible health-care systems that provide people-centred care for patients with complex, lifelong conditions. Governments and other partners have a key role to play in addressing the unnecessary social consequences of psoriasis by the challenging the myths and behaviours that lead to the exclusion of patients from health-care settings and daily life.

\section{Dr Oleg Chestnov}

Assistant Director-General

Noncommunicable Diseases and Mental Health

World Health Organization 


\section{Acknowledgements}

This report was prepared by Irmina Maria Michalek and Belinda Loring, Department for Management of Noncommunicable Diseases, Disability, Violence and Injury Prevention, World Health Organization; and Swen Malte John, University of Osnabrueck, Germany

Contributions to the report were made by Matthias Augustin, Barbra Bohannan, Sara Conyers, Kathleen Gallant, Melancia Jaime, Janice Johnson, Gary Lai, Ulrich Mrowietz, Michael P Schön, Astrid Sibbes, Judy Wallace and Shi Xingxiang.

The following people provided helpful comments and expert technical review: Ragnar Akre-Aas, WolfHenning Boehncke, Lars Ettarp, Silvia Fernandez Barrio, Christopher Griffiths, Josef de Guzman, Mahira Hamdy El Sayed, Alison Harvey, Susanne Hedberg, Peter van de Kerkhof, Etienne Krug, Mark Lebwohl, Leticia Lopez, Alan Menter, Jörg Prinz, Lone Skov, Mona Ståhle, Cherian Varghese and Hoseah Waweru. 


\section{Acronyms and abbreviations}

$\begin{array}{ll}\text { BSA } & \text { body surface area } \\ \text { CLCI } & \text { cumulative life course impairment } \\ \text { DALY } & \text { disability-adjusted life year } \\ \text { DLQI } & \text { Dermatological Quality of Life Index } \\ \text { HRQoL } & \text { health-related quality of life } \\ \text { NCD } & \text { noncommunicable disease } \\ \text { NICE } & \text { National Institute for Health and Care Excellence } \\ \text { PASI } & \text { Psoriasis Area and Severity Index } \\ \text { QoL } & \text { quality of life } \\ \text { US } & \text { United States } \\ \text { UV } & \text { ultraviolet } \\ \text { WHA } & \text { World Health Assembly } \\ \text { WHO } & \text { World Health Organization } \\ \text { YLD } & \text { years lived with disability } \\ \text { YLL } & \text { years of life lost }\end{array}$




\section{Chapter 1. Introduction}

\section{What is psoriasis?}

Psoriasis is a chronic, noncommunicable, painful, disfiguring and disabling disease for which there is no cure and with great negative impact on patients' quality of life (QoL). It can occur at any age, and is most common in the age group 50-69 (1). The reported prevalence of psoriasis in countries ranges between $0.09 \%$ (2) and $11.4 \%$ (3), making psoriasis a serious global problem.

The etiology of psoriasis remains unclear, although there is evidence for genetic predisposition (4). The role of the immune system in psoriasis causation is also a major topic of research. Although there is a suggestion that psoriasis could be an autoimmune disease, no autoantigen that could be responsible has been defined yet. Psoriasis can also be provoked by external and internal triggers, including mild trauma, sunburn, infections, systemic drugs and stress (5).

Psoriasis involves the skin and nails, and is associated with a number of comorbidities. Skin lesions are localized or generalized, mostly symmetrical, sharply demarcated, red papules and plaques, and usually covered with white or silver scales. Lesions cause itching, stinging and pain. Between $1.3 \%$ (6) and $34.7 \%$ (7) of individuals with psoriasis develop chronic, inflammatory arthritis (psoriatic arthritis) that leads to joint deformations and disability. Between $4.2 \%$ and $69 \%$ of all patients suffering from psoriasis develop nail changes (8-10). Individuals with psoriasis are reported to be at increased risk of developing other serious clinical conditions such as cardiovascular and other noncommunicable diseases (NCDs) $(5,11,12)$.

Psoriasis causes great physical, emotional and social burden (13-15). QoL, in general, is often significantly impaired (16-23). Disfiguration, disability and marked loss of productivity are common challenges for people with psoriasis. There is also a significant cost to mental well-being, such as higher rates of depression, leading to negative impact for individuals and society $(24,25)$. Social exclusion, discrimination and stigma are psychologically devastating for individuals suffering from psoriasis and their families. It is not psoriasis causing the exclusion - it is largely society's reaction to it and this can change.

Treatment of psoriasis is still based on controlling the symptoms. Topical and systemic therapies as well as phototherapy are available. In practice, a combination of these methods is often used. The need for treatment is usually lifelong and is aimed at remission. So far, there is no therapy that would give hope for a complete cure of psoriasis. Additionally, care for patients with psoriasis requires not only treating skin lesions and joint involvement, but it is also very important to identify and manage common comorbidity that already exists or may develop, including cardiovascular and metabolic diseases as well as psychological conditions.

In 2015, the notion is that psoriasis is a complex disease leading to numerous consequences for patients' lives (Figure 1). 
Figure 1. Synopsis on psoriasis as a chronic disease with a high comorbidity

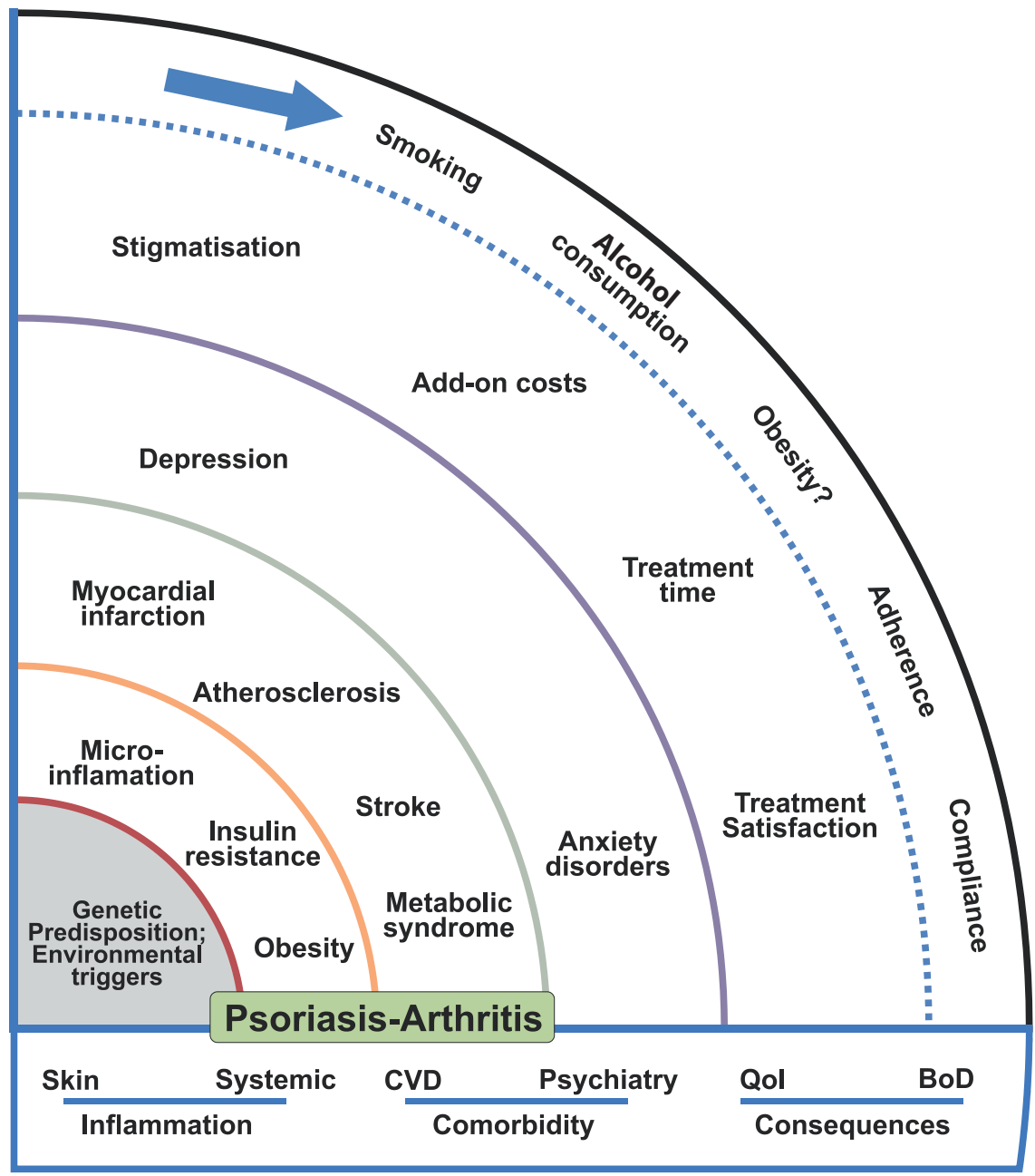

BoD, burden of disease; CVD, cardiovascular disease; QoL, quality of life Source: Mrowietz et al. 2014 (26).

\section{Why a global report on psoriasis?}

On 24 May 2014, the Sixty-seventh World Health Assembly of the World Health Organization (WHO) passed a resolution on psoriasis (WHA 67.9). All Member States recognized the burden of psoriasis and committed to increase their efforts to fight the stigma and unnecessary exclusion of people living with psoriasis. They recognized as well that too many people in the world suffer needlessly from psoriasis due to incorrect or delayed diagnosis, inadequate treatment options and insufficient access to care. The resolution requested WHO to prepare a global report on psoriasis, drawing attention to the public health impact of psoriasis. The resolution also encouraged Member States to engage in advocacy efforts, to raise awareness regarding the disease of psoriasis and fighting off stigmatization suffered by those with psoriasis.

WHO recognizes the urgent need to pursue multilateral efforts to raise awareness regarding the disease of psoriasis and to fight stigmatization suffered by those with psoriasis. This report is written to help raise awareness of the range of ways that psoriasis can impact on people's lives. It aims at empowering policymakers with practical solutions to improve the health care and the social inclusion of individuals with psoriasis - and other NCDs - in society. 


\section{Chapter 2. The burden of psoriasis}

Psoriasis occurs worldwide. It affects men and women of all ages, regardless of ethnic origin, in all countries (1). Published data on the prevalence of psoriasis in countries vary between $0.09 \%$ (2) and $11.4 \%$ (3). In most developed countries, prevalence is between 1.5 and $5 \%$ (27). There is also evidence to suggest that the prevalence of psoriasis may be increasing (3). Many studies have demonstrated that psoriasis can impact substantially on QoL, even when a relatively limited body surface area (BSA) is affected $(16,17,22,28-32)$.

\section{Incidence and prevalence}

There are very few studies on the incidence ${ }^{1}$ of psoriasis. Registration of psoriasis cases is not compulsory, meaning reliable data are difficult to find. A review of published literature revealed only a handful of credible studies on the incidence of psoriasis. One study showed that the overall sex- and age-adjusted incidence rate of psoriasis in Minnesota in the United States, between 1980 and 1983, was estimated at 0.60 per 1000 person-years (33). A study of 511532 individuals in Italy between 2001 and 2005 reported an incidence of psoriasis (adults receiving a first-ever diagnosis of psoriasis) of 2.30-3.21 cases per 1000 person-years (12). In 2012, a 2-week psoriasis screening study via medical consultation was performed in three countries simultaneously - Algeria, Tunisia and Morocco, where incidence of psoriasis was estimated at $10.36,13.26$ and 15.04 per 1000 , respectively (34).

Relatively more studies have focused on the prevalence of psoriasis. A review of published literature found 68 full articles and reports estimating prevalence rates for 20 countries (Table 1). It should be noted, however, that the data they contain are extremely difficult to compare with each other, due to the different methodologies of the studies and their limitations. The main problems are differences in the definition of prevalence (point prevalence, cumulative prevalence, period prevalence), case definition of psoriasis (selfreported, physician diagnosed), the population ages studied (children only, adults only, any age group) and the sampling techniques (questionnaires, clinical examination, combination of clinical examination and questionnaire, registry data). This difference in methodology clearly impacted on the prevalence rates. Depending on the region, the prevalence studies varied from $0.09 \%$ in the United Republic of Tanzania (2) to $11.4 \%$ in Norway (3). A very weak correlation between geographic latitude and psoriasis prevalence was found (35). Psoriasis appears to occur most commonly in populations of northern Europe $(3,36)$ and least in populations of eastern Asia (37-45) Some studies investigated the ethnic differences in the prevalence of psoriasis. According to a 2001 study in the United States, people with Caucasian or Black ancestry and others had a prevalence of $2.5 \%, 1.3 \%$ and $1.0 \%$, respectively (14). In another United States study from 2009-2010, these differences were higher, with the prevalence for Caucasians, Blacks, Hispanics and others at $3.6 \%, 1.9 \%, 1.6 \%$ and $1.4 \%$, respectively (46).

Incidence and prevalence are related terms. Prevalence refers to the proportion in a population found to have a condition out of the total number of people studied, while incidence refers to new cases within a specified period (usually one year) divided by the size of the population. 
Table 1. Summary of studies on the prevalence of psoriasis

\begin{tabular}{|c|c|c|c|c|c|c|}
\hline Geographic location & Year(s) of the study & Sample size & Estimate & Female & Male & $\begin{array}{c}\text { Ages of subjects } \\
\text { (years) }\end{array}$ \\
\hline \multicolumn{7}{|c|}{ Children } \\
\hline China, Taiwan (39) & 2004 & 4067 & $0.00 \%$ & & & $6-11$ \\
\hline China, Taiwan (38) & 2005 & 3273 & $0.00 \%$ & & & $6-11$ \\
\hline Egypt (47) & $2008-2009$ & 2194 & $0.05 \%$ & & & $<18$ \\
\hline Egypt (48) & $2011-2012$ & 6162 & $0.06 \%$ & & & $6-12$ \\
\hline Germany (49) & 2005 & 306020 & $0.71 \%$ & $0.76 \%$ & $0.66 \%$ & $<18$ \\
\hline Germany (50) & 2007 & 1215684 & $0.40 \%$ & $0.44 \%$ & $0.35 \%$ & $<18$ \\
\hline Germany $(11,51)$ & 2009 & 293181 & $0.45 \%$ & & & $<18$ \\
\hline Germany (52) & $\ldots$ & 16500 & $1.37 \%$ & & & $0-17$ \\
\hline Italy (53) & 2006 & 145233 & $0.09 \%$ & & & $0-14$ \\
\hline Italy (54) & 2012 & 145233 & $0.2 \%$ & & & $0-14$ \\
\hline Sweden (55) & $1975-1976$ & 8298 & $0.30 \%$ & $0.50 \%$ & $0.10 \%$ & $12-17$ \\
\hline \multicolumn{7}{|c|}{ Adults } \\
\hline Australia (56) & $\ldots$ & 1037 & $2.30 \%$ & & & $\ldots$ \\
\hline Australia (57) & 1996 & 416 & $4.5 \%$ & & & $\geq 18$ \\
\hline Australia (58) & 1997-1998 & 1457 & $6.6 \%$ & $4.5 \%$ & $8.9 \%$ & $\geq 20$ \\
\hline Brazil (13) & 2011 & 12000 & $1.3 \%$ & & & $\geq 18$ \\
\hline Croatia (59) & 1987 & 6711 & $1.21 \%$ & & & $>18$ \\
\hline Denmark (60) & 1978 & 3892 & $3.73 \%$ & $3.29 \%$ & $4.18 \%$ & $16-99$ \\
\hline France (61) & 2005 & 6887 & $5.17 \%$ & & & $\geq 15$ \\
\hline Germany (62) & $2004-2009$ & 90880 & $2.03 \%$ & $1.78 \%$ & $2.24 \%$ & $16-70$ \\
\hline Germany (63) & $2001-2005$ & 48665 & $2.10 \%$ & $1.9 \%$ & $2.3 \%$ & $16-70$ \\
\hline Italy (64) & 2003 & 3660 & $3.10 \%$ & & & $\geq 45$ \\
\hline Norway (3) & 2008 & 10302 & $11.43 \%$ & $10.8 \%$ & $12.1 \%$ & $20-79$ \\
\hline Norway (65) & 1979-1980 & 14667 & $4.82 \%$ & $4.85 \%$ & $4.79 \%$ & $20-54$ \\
\hline Norway (36) & $2000-2001$ & 18747 & $6.1 \%$ & & & $30-75$ \\
\hline Norway (66) & 1998 & 8045 & $4.2 \%$ & & & $19-31$ \\
\hline Sweden (67) & $2004-2005$ & 4875 & $3.9 \%$ & & & $18-84$ \\
\hline United Kingdom (68) & $\ldots$ & 58257 & $1.3 \%$ & & & $18-64$ \\
\hline United States of America (14) & 2001 & 27220 & $2.21 \%$ & $2.5 \%$ & $1.9 \%$ & $\geq 18$ \\
\hline United States of America (46) & $2009-2010$ & 6216 & $3.2 \%$ & $3.1 \%$ & $3.6 \%$ & $20-59$ \\
\hline United States of America (69) & $2003-2004$ & 2984 & $3.15 \%$ & $3.18 \%$ & $3.11 \%$ & $20-59$ \\
\hline United States of America (70) & $1998-2010$ & 121701 & & $1.32 \%$ & & $30-55$ \\
\hline United States of America (70) & $1991-2005$ & 116686 & & $1.37 \%$ & & $25-42$ \\
\hline United States of America (70) & $1986-2010$ & 51529 & & & $1.25 \%$ & $40-75$ \\
\hline United States of America (71) & 2011 & 799607 & $0.51 \%-1.13 \%$ & & & $\geq 65$ \\
\hline United States of America (72) & $2003-2006,2009-2010$ & 10676 & $3.10 \%$ & $3.0 \%$ & $3.1 \%$ & $20-59$ \\
\hline United States of America (73) & 2001 & 2443 & $1.3 \%$ & & & $\geq 18$ \\
\hline United States of America (73) & 2001 & 21921 & $2.5 \%$ & & & $\geq 18$ \\
\hline United States of America (74) & $2001-2002$ & 2619719 & $0.91 \%$ & & & $\ldots$ \\
\hline United States of America (74) & $2001-2002$ & 2872333 & $1.06 \%$ & & & $\ldots$ \\
\hline United States of America (75) & $1991-2005$ & 84039 & & $2.58 \%$ & & $41-58$ \\
\hline \multicolumn{7}{|c|}{ All ages } \\
\hline China (37) & 1984 & 6617917 & $0.123 \%$ & 0.124 & 0.168 & $0-65+$ \\
\hline China (40) & $\ldots$ & 30935 & $1.49 \%$ & & & all ages \\
\hline China, Taiwan (41) & $2000-2006$ & 5864 & $0.19 \%$ & $0.16 \%$ & $0.23 \%$ & all ages \\
\hline China, Taiwan (76) & 2006 & 23000000 & $0.235 \%$ & & & all ages \\
\hline China (42) & 1974-1981 & 670000 & $0.35 \%$ & & & $\ldots$ \\
\hline China (43) & $\ldots$ & 17345 & $0.47 \%$ & & & all ages \\
\hline China (44) & $\ldots$ & 7747 & $2.14 \%$ & & & $12-20$ \\
\hline Denmark, Faroe Islands (77) & 1947-1948 & 10984 & $2.84 \%$ & & & all ages \\
\hline
\end{tabular}




\begin{tabular}{|c|c|c|c|c|c|c|}
\hline Egypt (78) & 1994-1996 & 8008 & $0.19 \%$ & & & all ages \\
\hline Germany (79) & 2005 & 1344071 & $2.53 \%$ & $2.57 \%$ & $2.79 \%$ & all ages \\
\hline Germany (80) & 2003 & 2238000 & $2.0 \%$ & & & all ages \\
\hline Italy (81) & 2006 & 4109 & $2.9 \%$ & & & all ages \\
\hline Japan (45) & $2010-2011$ & 128000000 & $0.44 \%$ & & & all ages \\
\hline Norway (82) & 1985 & 10576 & $1.41 \%$ & $1.45 \%$ & $1.37 \%$ & all ages \\
\hline Norway (83) & 1991 & 2508 & $1.40 \%$ & & & all ages \\
\hline Norway (83) & 1991 & 442 & $1.10 \%$ & & & all ages \\
\hline Poland (84) & $2005-2009$ & 2161832 & $1.45 \%$ & $1.46 \%$ & $1.43 \%$ & all ages \\
\hline Portugal (85) & 1994 & 1037 & $1.9 \%$ & & & all ages \\
\hline Spain (86) & 1998 & 12938 & $1.43 \%$ & $1.40 \%$ & $1.46 \%$ & all ages \\
\hline Spain (87) & 2013 & 12711 & $2.31 \%$ & $1.9 \%$ & $2.7 \%$ & all ages \\
\hline Sri Lanka (88) & 1997 & 1806 & $0.44 \%$ & & & all ages \\
\hline Sweden (89) & 2001-2007 & $\ldots$ & $1.35 \%$ & & & all ages \\
\hline Sweden (90) & 1998-2010 & $\ldots$ & $1.95 \%$ & & & all ages \\
\hline Tanzania, United Republic of (2) & 1994 & 1114 & $0.09 \%$ & & & all ages \\
\hline Tunisia (91) & $\ldots$ & 5778 & $0.57 \%$ & & & all ages \\
\hline United Kingdom (92) & 2009 & 7520293 & $1.87 \%$ & $1.9 \%$ & $1.8 \%$ & all ages \\
\hline United Kingdom (93) & $\ldots$ & 4390 & $1.71 \%$ & & & all ages \\
\hline United Kingdom (94) & 1987-2002 & 7533475 & $1.52 \%$ & & & all ages \\
\hline United Kingdom (95) & $\ldots$ & 29348 & $2.60 \%$ & & & all ages \\
\hline United Kingdom (96) & $2002-2003$ & 789335 & $0.8 \%$ & & & all ages \\
\hline United Kingdom (97) & 1999 & 252538 & $0.73 \%$ & & & all ages \\
\hline United States of America (98) & 1971-1974 & 20749 & $1.43 \%$ & & & $1-74$ \\
\hline United States of America (99) & 2009 & 2573 & $5.1 \%$ & & & all ages \\
\hline
\end{tabular}

Note:...$=$ no data.

Psoriasis is considered equally prevalent in both sexes (5). However, out of all studies that reported prevalence by sex (Figure 2), some studies indicated that psoriasis is more common in men. Quoted values are not statistically significant. This issue needs further investigation, in particular, the differentiation of genetic and behavioural factors.

Figure 2. Prevalence of psoriasis by sex (year of data survey given; not of publication)

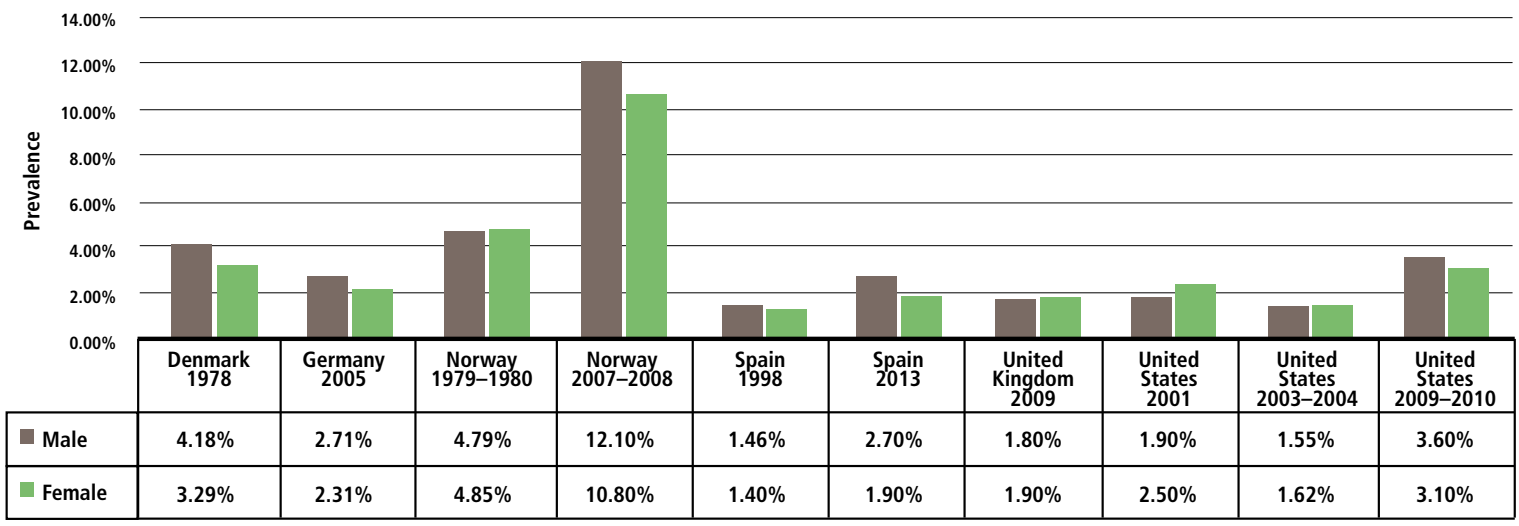


Psoriasis can occur at any age. While some studies indicated the average age of onset for psoriasis was 33 years of age, and $75 \%$ of cases occurred before 46 years of age (93), others suggested that the onset of psoriasis was bimodal with two peaks of the disease - the first between 16 and 22 and the second between 57 and 60 years of age (100).

Psoriasis also occurs in children. However, there are few studies on the incidence or prevalence of psoriasis in children, and those that do exist reveal variations between almost absence of juvenile psoriasis in Taiwan, China $(38,39)$ and 1.37\% lifetime prevalence in 0-17-year-old children in Germany (52). The largest study on prevalence among children was carried out in Germany in 2007 (49). Data collected from a health insurance company database of about 1.3 million individuals showed the prevalence of psoriasis in children younger than 18 years of age was $0.40 \%$, and increased roughly linearly over the life course. In 2008-2009, a study of 2194 children in Egypt (47) found that the prevalence of psoriasis among people 18 years of age and younger was $0.05 \%$.

\section{Is psoriasis becoming more or less common?}

Tracking trends in incidence and prevalence of psoriasis is difficult, due to the different methodologies of research on this issue. However, an apparent upward trend is observed in several countries. The prevalence of psoriasis in China in 1984 was $0.17 \%$, while 25 years later, another study found it to be $0.59 \%(37,43)$. The prevalence in Spain in 1998 was $1.43 \%$, while 15 years later it was reported as $2.31 \%(86,87)$. Data on the prevalence in the United States from the National Health and Nutrition Examination Survey indicated an increase in prevalence from 1.62\% to 3.10\% from 2004 to $2010(46,69)$. However, different methodologies of conducting these studies, especially in view of the various case definitions of psoriasis, do not allow for a clear assessment of the increasing trend.

The most instructive study of trends in prevalence is a 30-year follow-up of a population-based cohort in Tromsø, Norway (3). Analyses of trends in prevalence during 1979-2008 indicate that selfreported lifetime prevalence of psoriasis (in the same cohort) has increased from $4.8 \%$ to $11.4 \%$.

\section{Global disability burden from psoriasis}

The Global Burden of Disease Study in 2010 (1) was an attempt at measuring the extent of disability or loss of health due to different diseases. One of the metrics commonly used for this measurement is the disability-adjusted life year (DALY). DALY equals the sum of years lived with disability (YLDs) and years of life lost (YLLS). One DALY equals one lost year of a healthy life.

\section{$D A L Y=Y L D+Y L L \quad 1 D A L Y=1$ lost year of healthy life}

The analyses of the Global Burden of Disease Study suggested that the burden of psoriasis is high (1). Global average DALY for psoriasis for 2010 was estimated at 1050 660, which is twice as much as for acute hepatitis $C$. The global burden of disease estimates for individual countries are presented on the map in Figure 3. 
Figure 3. World map showing the DALYs for psoriasis per 100 000, rates for all ages and both sexes

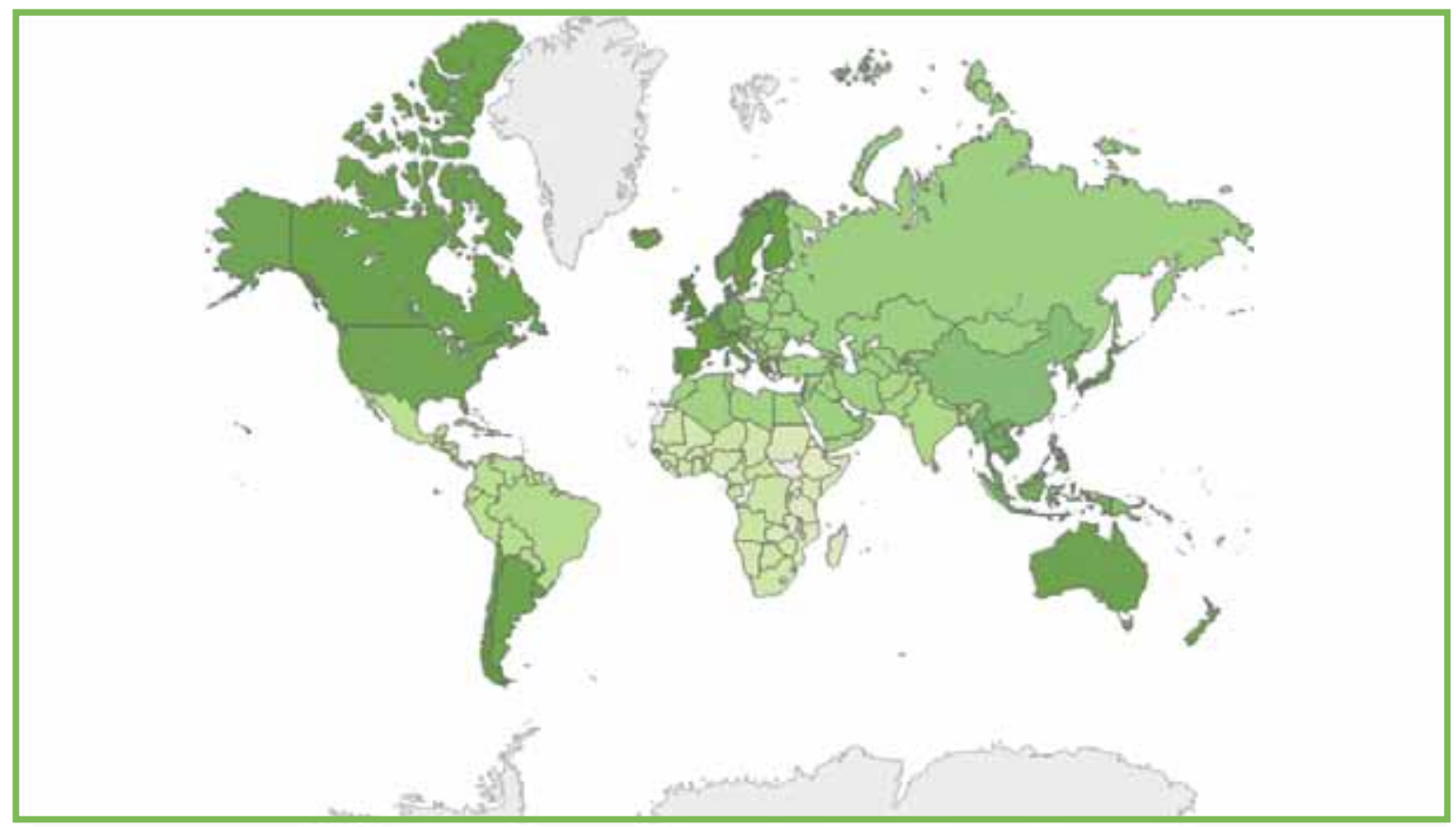

DALYs per 100000

$12109 \quad 19428$

Source: Adapted from IHME GBD 2010 (1).

The DALYs for both sexes increased linearly with increasing age up to 60 years. The study showed the greatest burden of disease occurred in the 50-69 years of age group and that psoriasis caused slightly higher DALYs burden in adult males than in adult women up to 75 years of age (Figure 4).

In the Global Burden of Disease Study, the specific patient burden of chronic skin diseases such as psoriasis may have been underestimated since the underlying disease weights were not derived from the affected patients. Several studies have shown that chronic skin diseases with high stigmatization are perceived in a significantly more negative manner by the patients than by the public. Thus, the limitations of the Global Burden of Disease Study reflect a major psychosocial problem for patients with psoriasis in general: the lack of awareness of their specific burden by others. Recent publications on the global burden of disease of psoriasis and skin diseases have outlined this discrepancy accordingly $(101,102)$. For this, any comparative analysis of disease burden between conditions needs to better balance between objective and subjective burden. 
Figure 4. Distribution of DALYs for psoriasis per 100 000, by gender and age group

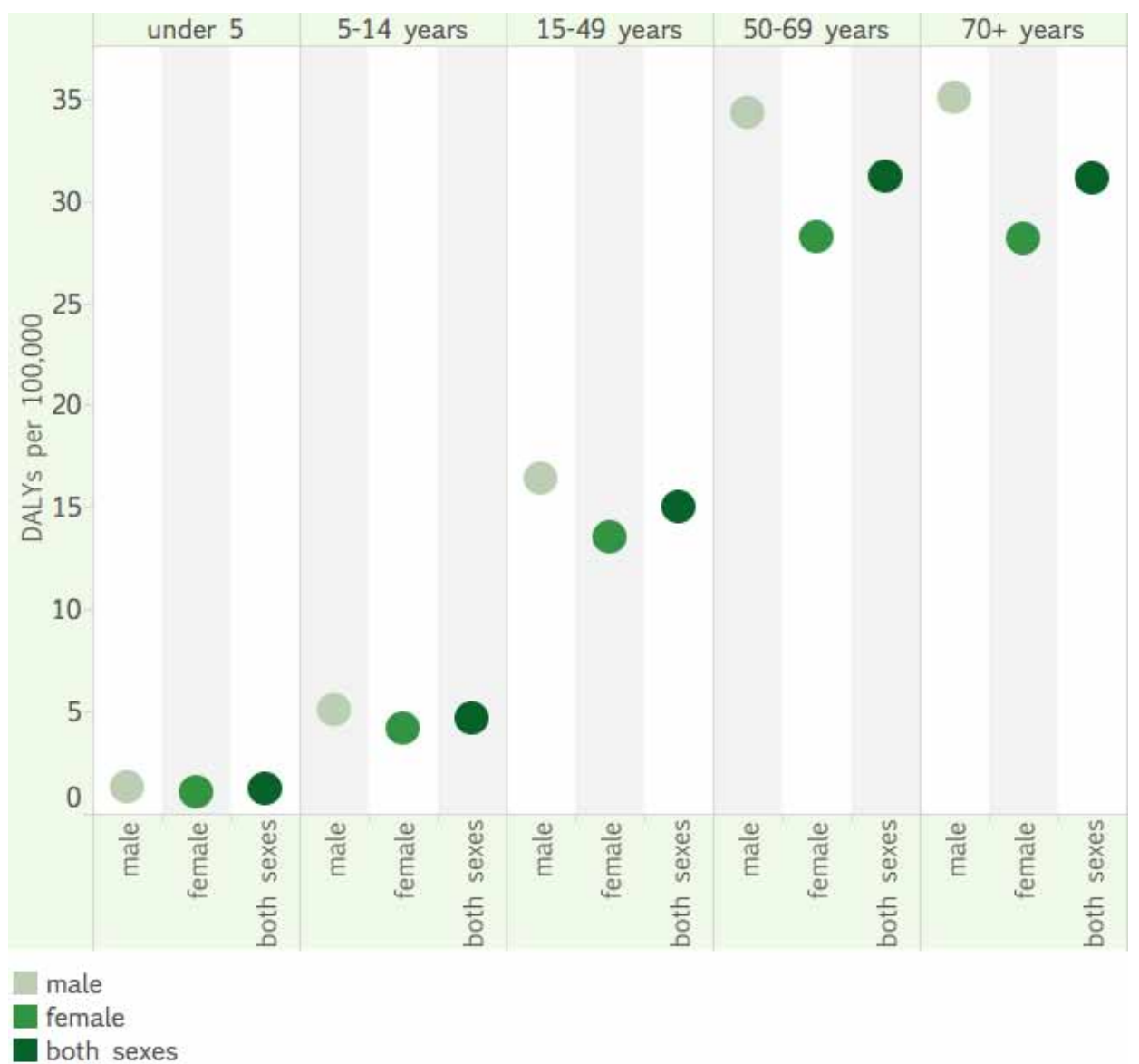

Source: Adapted from IHME GBD 2010 (1).

\section{Gaps in data}

Good epidemiological data are essential for disease control and appropriate health-care planning. This chapter illustrates the many gaps in psoriasis data, and dermatology remains one of the most neglected fields of epidemiological study. There is a need for better quality data on incidence and prevalence of psoriasis to understand better the size and distribution of the problem. The available prevalence data come from only 20 countries, meaning there are huge geographic gaps in knowledge, especially from low- and middle-income settings. In order to compare the incidence and prevalence of psoriasis between regions and to track their trends over time, data must be obtained in the same way in different places, reproducibly. Standardized measurements are needed, including uniform diagnostic assessment, definition of adulthood and case-finding methods, in order to provide further insight into dermatological problems such as psoriasis. The estimation of disease burden from psoriasis such as the $2010 \mathrm{Global}$ Burden of Disease Study should be based on improved, more patient-centred methods. This includes the consideration of disease-specific rather than generic measures. 


\section{Chapter 3. How does psoriasis affect peoples' lives?}

\section{Introduction}

Psoriasis is a chronic, noncommunicable, painful, disfiguring and disabling disease for which there is no cure, presenting without a single, typical clinical picture. It can manifest in many different forms. In addition to the involvement of skin and nails, inflammatory arthritis (psoriatic arthritis) may develop. Patients suffering from psoriasis are at higher risk of developing cardiovascular and other NCDs (103). Moreover, psoriasis affects mental health and people suffering from the disease experience significant social stigma.

In assessing the severity of psoriasis, more than 40 different tools are being used (104). Commonly used measures for scoring the severity of psoriasis include the Psoriasis Area and Severity Index (PASI), and the Physician Global Assessment. Clinicians assess the severity of the disease, taking into account the degree of scaling, redness, thickness of the skin lesions or the size of the BSA occupied by psoriasis. QoL measures are also important.

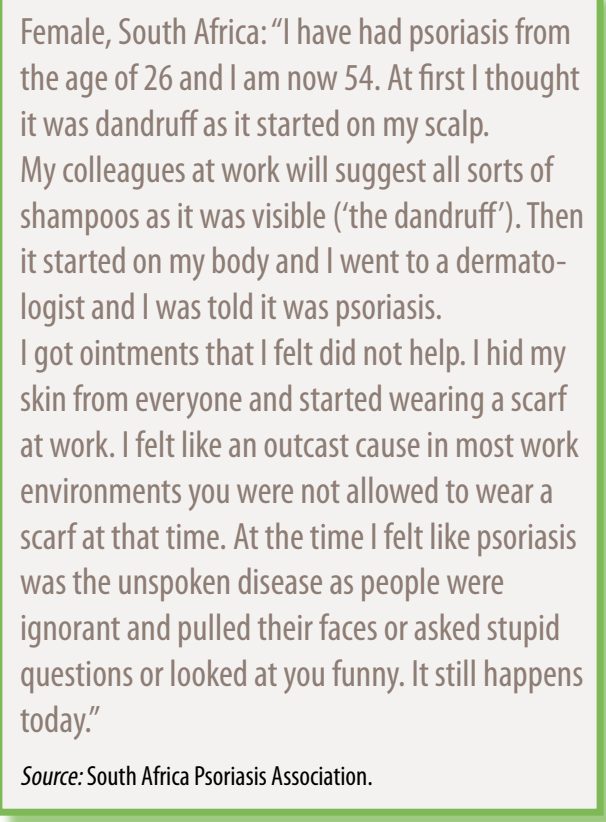

Female, South Africa:"I have had psoriasis from the age of 26 and I am now 54. At first I thought it was dandruff as it started on my scalp. My colleagues at work will suggest all sorts of shampoos as it was visible ('the dandruff'). Then it started on my body and I went to a dermatologist and I was told it was psoriasis.

I got ointments that I felt did not help. I hid my skin from everyone and started wearing a scarf at work. I felt like an outcast cause in most work environments you were not allowed to wear a scarf at that time. At the time I felt like psoriasis was the unspoken disease as people were ignorant and pulled their faces or asked stupid questions or looked at you funny. It still happens

Source: South Africa Psoriasis Association.

\section{Skin and nails}

Based on the type of skin lesions, location, the age of onset and course of disease, several clinical classifications of psoriasis are used (Table 2).

The most frequently reported symptoms connected to psoriasis are (105):

- scaling of the skin in $92 \%$

- itching in $72 \%$

- erythema in $69 \%$

- fatigue in $27 \%$

- swelling in $23 \%$

- burning in $20 \%$

- bleeding in $20 \%$ of individuals.

According to another study, flaking or scaling in the non-scalp area occurred in $89 \%$ and flaking or scaling of scalp areas in $62 \%$ of patients. Itching or scratching were observed in $87 \%$, rash in $74 \%$, skin pain in $62 \%$, bleeding in $58 \%$, redness in $57 \%$, flare-ups in $49 \%$, joint pain in $42 \%$, skin cracking in $39 \%$, dry skin in $34 \%$, physical discomfort in $32 \%$, burning in $28 \%$ and nail problems in $22 \%$ (7). 

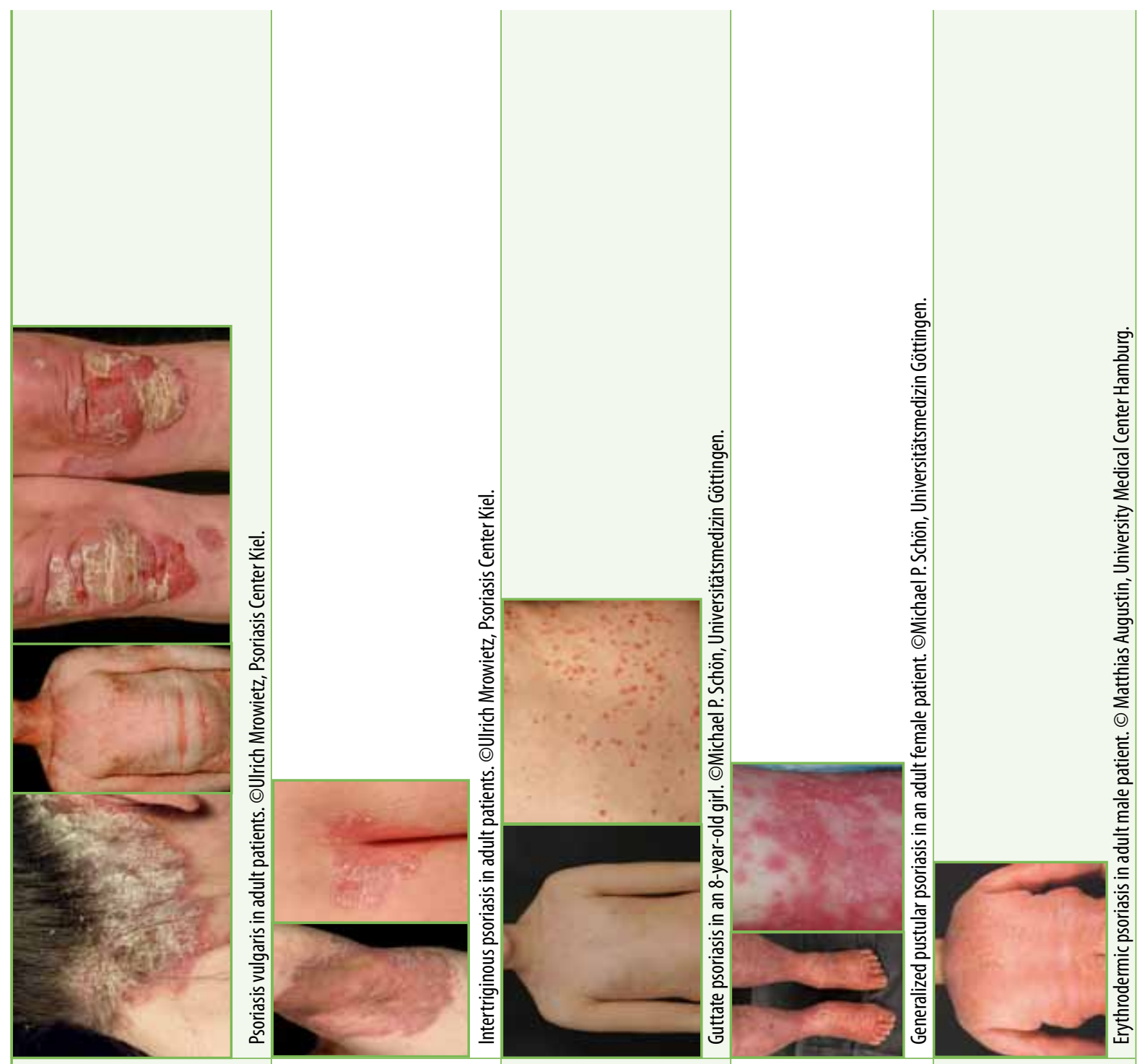

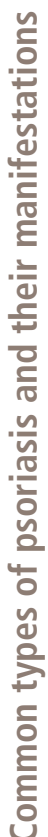
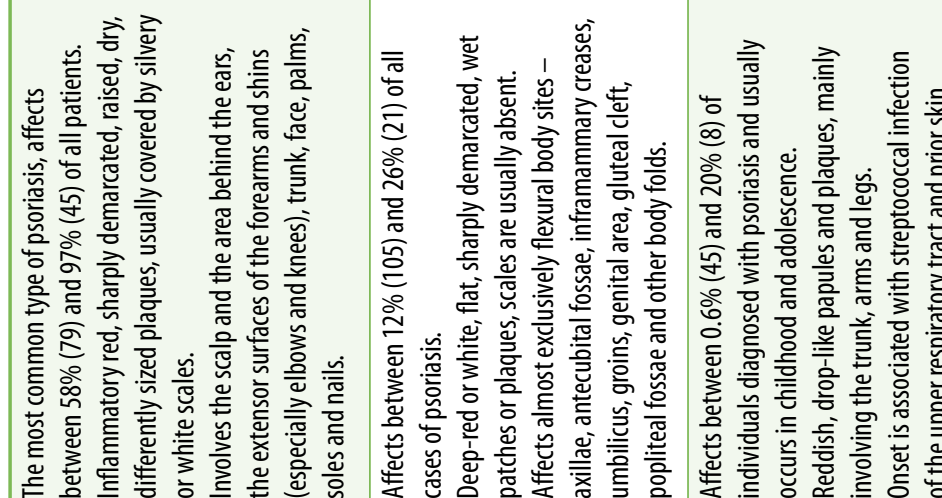

- 㝘
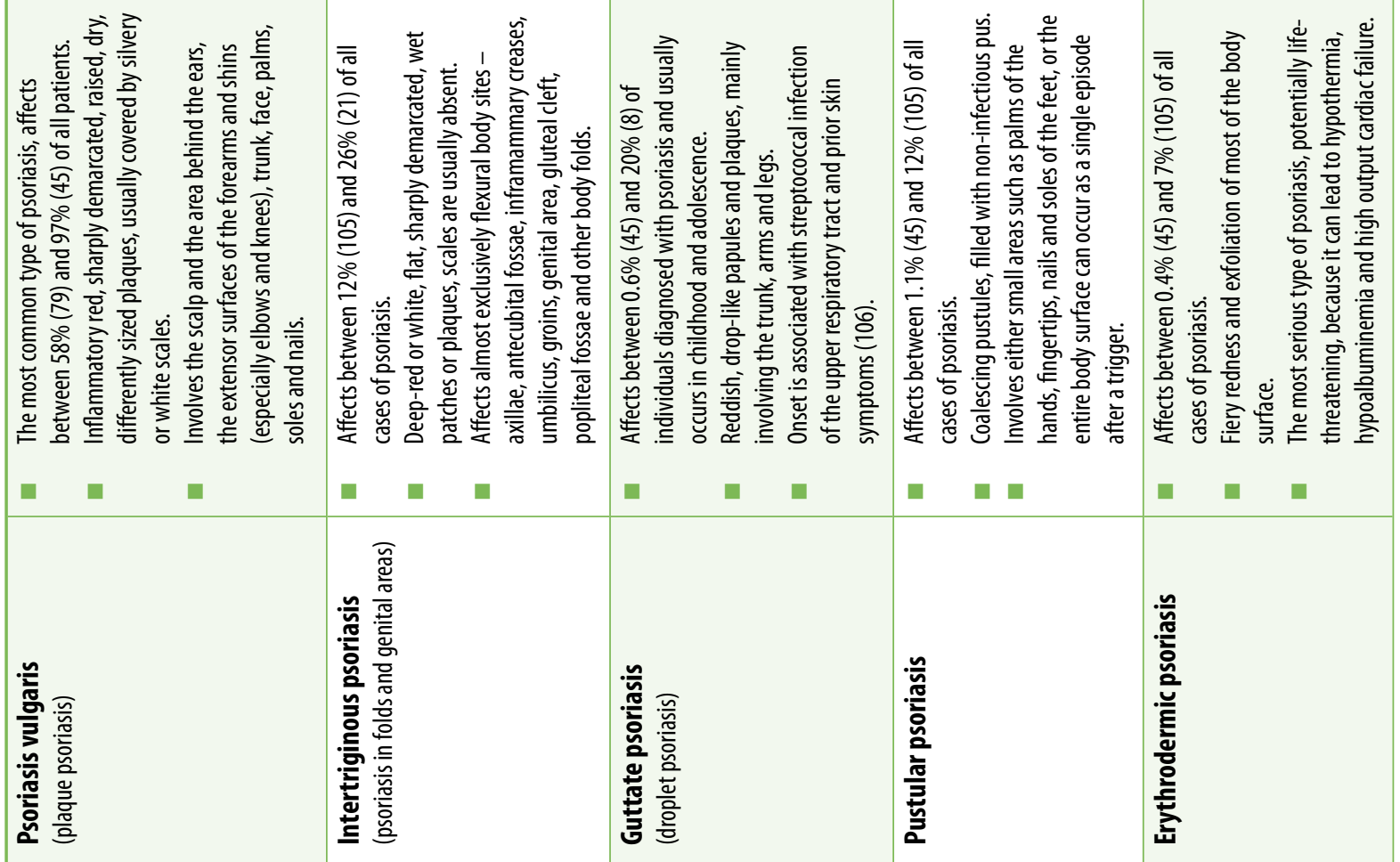
Based on a review of the literature, the prevalence of nail psoriasis ranges between $4.2 \%$ (8) and $69 \%$ (9) of all patients suffering from psoriasis. Nail psoriasis may occur with the involvement of the skin or it may occur alone, being the only symptom of psoriasis. Nail psoriasis is not only a problem of an aesthetic nature, but can also restrict manual dexterity. The nail disease may be acute or chronic, with varied severity. There may be involvement of only a single nail or of all nails associated with severe nail destruction or loss (Figure 5).

\section{Figure 5. Nail psoriasis}
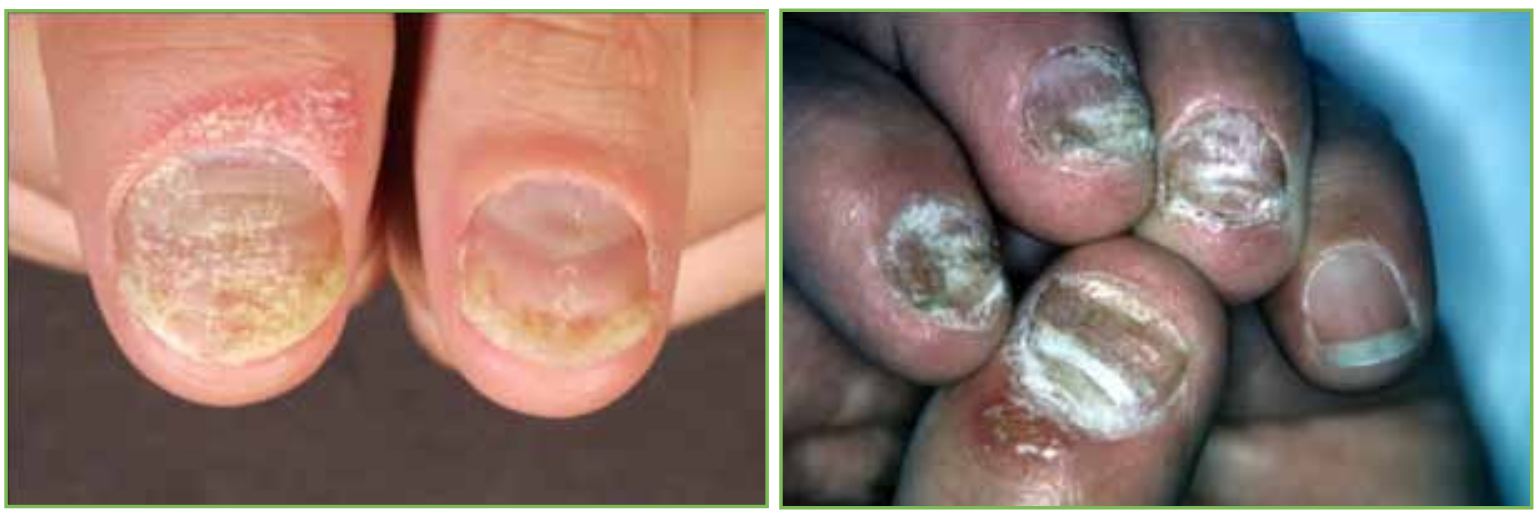

CMatthias Augustin, University Medical Center Hamburg.

Nail psoriasis may be a predisposing factor for fungal or bacterial infections, which occur in $4.6 \%$ to $30 \%$ of cases of nail psoriasis (107).

Patients suffering from nail psoriasis have significantly worse psoriasis severity scores, compared to patients without nail involvement (108). In addition, they report poorer QoL and a greater number of days unfit for work (108). These patients were also more likely to be admitted to the hospital and more often suffered from psoriatic arthritis.

\section{Psoriatic arthritis}

In addition to the skin, psoriasis can be associated with an inflammatory arthritis known as psoriatic arthritis, which involves the joints of the spine and other joints. This occurs without presence of specific antibodies in the blood (seronegative spondyloarthropathy). The rheumatoid factor (antibody occurring in rheumatoid arthritis) is also negative.

A review of the literature showed that psoriatic arthritis affects between $1.3 \%$ (6) and $34.7 \%$ (7) of patients diagnosed with psoriasis. There are no data on sex predilection. In a United States population, it was observed that psoriatic arthritis occurred more frequently in Caucasian patients than in other ethnic groups (109). Two large consecutive German studies from dermatological practices that assessed the prevalence of arthritis from examinations by rheumatologists in 2005 and 2007 was 20.6\% (10) and $19.6 \%(110)$, respectively.

The clinical symptoms are variable, however, peripheral arthritis, spondylitis, enthesitis (inflammation of the sites where tendons insert into the bone), arthritis in the fingers and dactylitis (profuse swelling of the fingers or toes) are considered to be most common (Figure 6). Psoriatic arthritis can lead to chronic pain and change in physical appearance. Patients suffering from psoriatic arthritis have reduced physical fitness, compared to psoriasis patients without it (22). Typically, psoriatic arthritis occurs in conjunction with longstanding skin lesions, although rarely it occurs alone, in the absence of psoriasis. 
Figure 6. Psoriasis arthritis
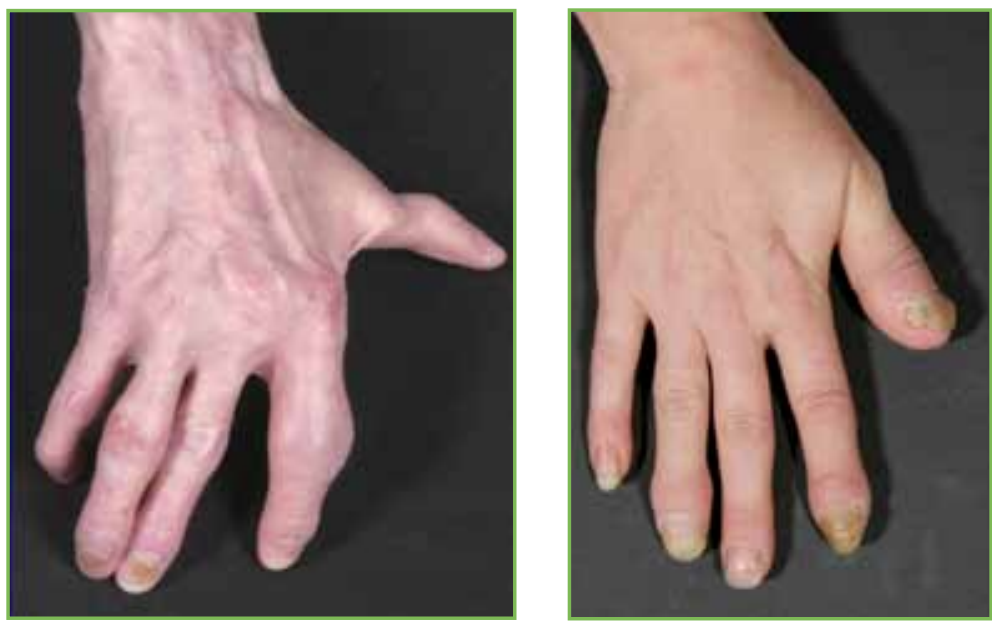

CMatthias Augustin, University Medical Center Hamburg.

\section{Associated diseases}

Numerous studies have reported the coexistence of psoriasis and other serious systemic diseases, most often mentioned are cardiovascular diseases, metabolic syndrome, including hypertension, dyslipidemia and diabetes mellitus, and Crohn's disease. Even children show increased rates of comorbidity compared to unaffected infants, or those with atopic eczema $(11,49)$.

Most publications discuss the association between cardiovascular disease and psoriasis. Patients diagnosed with psoriasis have an increased burden of subclinical atherosclerosis and vascular inflammation (111). They also have significantly higher levels of serum lipids, including triglycerides and total cholesterol, compared to healthy individuals (112). Moreover, psoriasis is associated with atrial fibrillation and stroke, which may be aggravated in young patients (113). However, it should be noted that at present it is not known whether psoriasis is an independent risk factor for the development of cardiovascular disease.

Obesity or weight gain has been shown to be an independent risk factor for psoriasis. Tobacco smoking is another risk factor (114). Frequency of metabolic syndrome, depression and erectile dysfunction has also been found to be significantly higher in patients diagnosed with psoriasis (115). In some diseases and subgroups of patients, psoriasis has been shown to be an independent risk factor for non-alcoholic fatty liver disease (116). In spite of a high number of studies on the association of psoriasis with comorbidity, the causality and independence on some associated diseases remain unclear and need further research $(117,118)$.

\section{Psychological and mental health}

Psoriasis is not only a disease that causes painful, debilitating, highly visible physical symptoms. It is also associated with a multitude of psychological impairments. For many reasons, psoriasis can be psychologically devastating. Patients' lives become especially difficult when psoriasis is present in highly visible areas of the skin such as the face and hands. Related psychological problems can affect every day social activities and work. It causes embarrassment, lack of self-esteem, anxiety and increased prevalence of depression $(24,25)$. Patients with psoriasis report experiencing anger or helplessness, and they disclose a higher rate of suicidal ideations than other patients. In a study of 127 patients with psoriasis, $9.7 \%$ reported a wish to be dead and $5.5 \%$ reported active suicidal ideation at the time of study (119). 


\section{Influences from the workplace}

In the workplace, psoriasis may be triggered or aggravated by mechanical or other physical impact on unprotected body locations (120). In patients who claimed occupational hand dermatitis, psoriasis was found to be the cause of the disease in 3.8\% (121)-6.5\% (122) of cases. Special gloves and other personal protective equipment may reduce lesions and enable the person to continue working, which otherwise may be jeopardized $(121,123)$.

\section{Social participation}

Psoriasis can affect relationships at home, school or work as well as sexual relationships and thus reduce QoL and cause psychological strain $(15,17-19,32,124-128)$. Patients are frequently stigmatized and excluded from normal social environments, including schools, workplaces and swimming pools. As a result, they often avoid social activities and commonly report experiencing loneliness, isolation, feelings of being unattractive and frustration.

A study conducted in the United States evaluated which spheres of patients' lives suffered most (7). Seven impact areas were considered: emotional (mood, feelings); social (friends, activities); the family (activities, responsibilities); professional (work, career); physical functioning; sexual intimacy; and educational life. The results showed that $98 \%$ of patients reported that psoriasis impacted on their emotional life, $94 \%$ on their social life, $70 \%$ on family life, $68 \%$ on their professional career, $38 \%$ on physical functioning, $17 \%$ on sexual intimacy, and $21 \%$ on their educational life. These values were all higher for patients with psoriatic arthritis.

The lost opportunities and the burden from disease over a significant portion of a lifetime can be cumulative and in many cases are irreversible.

Gary, with a genuine passion for swimming, has been a chronic patient of psoriasis since 23. Gary was not admitted to public swimming pools as swimmers made complaints to lifeguards. Even though the lifeguards know that psoriasis isn't contagious and won't be transmitted through water, they couldn't help but settle the situation by asking him to leave.... Moderate sunbathing can benefit psoriasis. Gary headed to a public park for sunbathing on a Sunday morning. When Gary revealed his skin, with red patches on the upper trunk, the mother of a little girl walked away with her daughter. Gary tried to explain to her that one couldn't catch psoriasis or spread it to others, yet the young lady turned a deaf ear to what he said and refused to believe it.

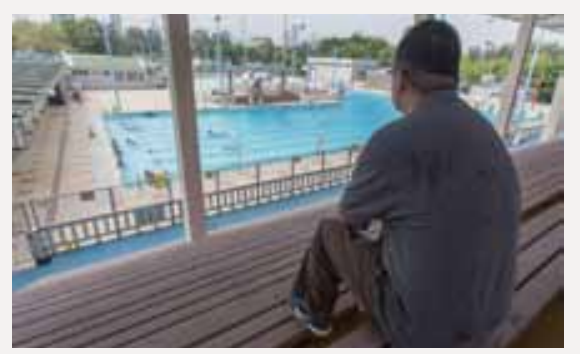

Source: @ Hong Kong Psoriasis Patients Association.

\section{Socioeconomic burden}

In patients with psoriasis, functional impairment, lost opportunities in professional life and elevated economic burden for treatment expenses can add to significant socioeconomic burden on an individual level (129-131). The costs of psoriasis are significant for both patients and the health-care system. The annual cost of psoriasis in the United States was estimated at US\$ 11.5 billion in 2008, with patient outof-pocket costs accounting for $55 \%$ of the total direct costs of the disease $(132,133)$. Survey data from the United States indicate that psoriasis patients pay on average US\$2528 out-of-pocket each year on psoriasis care, $34 \%$ of which is on prescription and over-the-counter medicines (134). In Switzerland, outof-pocket expenses for ambulatory care per patient in 2005 ranged from CHF 600-1100 per year for mild psoriasis to CHF 2400-9900 for severe psoriasis (135). 
Jimmy, United States of America, suffers from severe psoriasis affecting $90 \%$ of his body. He is currently homeless, after losing his ability to work from his painful psoriatic plaques affecting his hands. He has been denied a bed in a shelter because the staff were concerned his skin lesions were contagious. Jimmy currently lacks any effective treatment and struggles daily to not only provide for himself, but treat his painful skin.

Source: National Psoriasis Foundation, United States.
Inability to work due to psoriasis increases with psoriasis severity. In one German study, employed patients lost a mean of 4.9 working days per year due to psoriasis (23). For severe psoriasis, the incidence of hospitalization is almost twofold higher than for mild psoriasis (136). In addition, patients suffering from severe disease report a greater number of days absent from work or school due to psoriasis (136).

On the societal level, psoriasis, due to its high prevalence and marked direct and indirect costs, can result in considerable economic burden for tax payers, patients and society in general $(129,131,137,138)$.

\section{Measuring the impact of psoriasis on quality of life}

In addition to the evaluation of clinical manifestations, a health-related quality of life (HRQoL) measure is an important element in assessing the advancement of the disease and its impact on patients' health and well-being. QoL tools estimate the impact of the disease on the physical, mental, functional and social wellbeing from the patients' own perspectives. The Dermatology Life Quality Index (DLQI), despite methodological limitations, is currently the most frequently used method of evaluating QoL for patients with different skin conditions.

HRQoL is significantly impaired in patients with psoriasis. Factors such as disease severity, gender, age, anatomical sites of lesion, involvement of comorbidity (e.g. arthritis) and psychological distress can all be associated with reduced HRQOL in people with psoriasis. Burden from treatment and time needed for daily treatment are also major predictors of reduced HRQoL (139). Several studies showed evidence of a higher impact on QoL for females (139), whereas other studies have not found this difference. By contrast, an Iranian study on psoriasis patients showed that the negative impact on patients' QoL was higher for men than women (DLQI 11.0 versus 7.0) (21). The study also noted that the impact on QoL increased with the number of areas involved by the disease. The highest negative impact on QoL
Astrid, female, 57, Netherlands: "Having a serious skin disease at a young age is very difficult. Having psoriasis means that in the classroom no one wants to sit next to you. Having psoriasis means never to be invited to a birthday party and nobody wants to come to your birthday party. Having psoriasis means not being allowed to join the swimming lessons. Having psoriasis means not to be able to join a sports club etcetera. ... I fell in love with a nice man. He knew about psoriasis, because of his whole family suffered from psoriasis. After we married, we decided not to have children. We both have a sincere psoriasis and we don't want to give this to a child. We didn't want risk a child having a terrible life. This was very difficult to decide. Having no children means that you never have children in your house. No friends coming by, no children in law, no grandchildren. We have no people around the house and are just two people sitting at the Christmas dinner. Finding a job was very difficult. People suffering from psoriasis are not wanted. Another problem was finding a house. We wanted to buy a house, but because of the chronic disease, we were not able to get a mortgage. Now we have to pay a very high rental price, which means we are not able to go on holidays etc. ... There are also practical difficulties. When I want to go to a hairdresser it always gives big problems. Hairdressers don't like people with psoriasis. When I go shopping for clothes, I am not allowed to try some. When you go to the fitting room, you are not allowed to give the clothes back if they don't fit. You have to buy them, even if they don't fit. ... If I had no psoriasis, my life was probably complete different: Maybe we lived in a nice house. Probably we had a family: children and grandchildren. Maybe I had the job that I was educated for. Without psoriasis we could have a normal life."

Source: Psoriasis Vereniging Nederland 
was observed when the neck/décolletage region or hands were involved, and the lowest when the groin was involved.

A study conducted on a large population of European psoriasis patients showed that the overall impact of psoriasis increased in combination with the severity of the disease (105). Psoriasis was a significant problem for $15 \%$ of patients with mild psoriasis, $23 \%$ with moderate psoriasis and $51 \%$ with severe psoriasis. In addition, $48 \%$ of patients reported that their disability due to psoriasis had a modest impact on activities of daily living. To a lesser extent, disability also influenced career, school and relationships with friends. Several daily activities were adversely affected by psoriasis, including clothing choice (54\%), the need for more baths (45\%), washing/changing clothes more often (40\%), sport activities (38\%), sleep disorders (34\%) inhibiting work/school activities (27\%), sexual difficulties $(27 \%)$ and social relations (26\%). A study conducted in Malaysia showed similar results, with only $5.6 \%$ of patients reporting that

Dai, 26, China, suffers from erythrodermic psoriasis and pustular psoriasis. Dai has never entered any formal employment. He now sells honey online, but still has to rely on financial assistance from his parents for living and hospital, they were turned away by taxi drivers on their way and also by innkeepers.

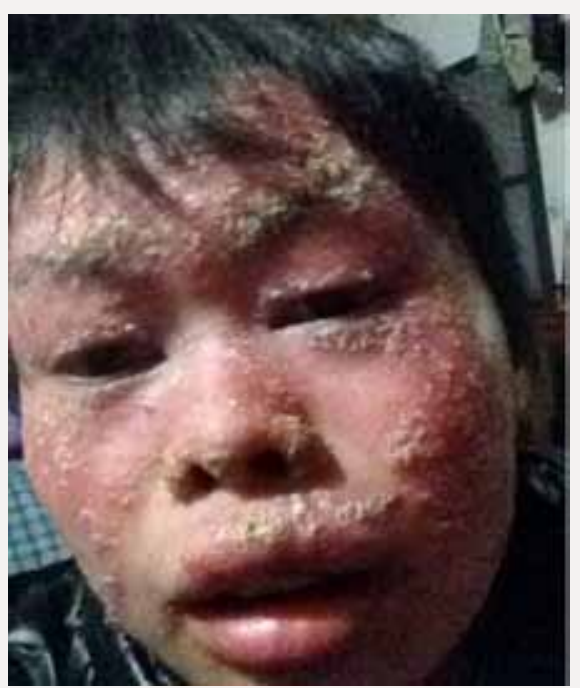

Source: National Psoriasis Foundation, United States. treatment. In 2015 when his mother took him to

psoriasis had no effect on their QoL (22). A study conducted in Germany also found that psoriasis had a negative impact on QoL for the majority of patients. Only $15.2 \%$ reported that psoriasis had no effect on their QoL (23).

However, it is important to note that in many studies, the correlation of impaired QoL scores with current clinical severity is low, indicating the impact of psoriasis on the individual goes beyond the apparent severity of skin lesions (141). Additionally, stigmatization and QoL burden associated with psoriasis can have a sustained effect over the course of a patient's lifetime. The chronic disability caused by psoriasis is referred to as the "cumulative life course impairment of psoriasis" (CLCI) (20). $\mathrm{CLCl}$ is a key concept of psoriasis care because it indicates that this chronic disease, which can stretch over the period from childhood to old age, can lead to irreversible burden and lost opportunities. Thus, even in the absence of life-threating conditions or physical scarring, there is an urgent need for early intervention and evidence-based psoriasis treatment in order to avoid long-term suffering, disease progression and escalation of $\mathrm{CLCl}$. In practice, indicators for patients at risk of $\mathrm{CLCl}$ can be detected, patients treated and potential $\mathrm{CLCl}$ prevented (142).

Studies on the impact of psoriasis on QoL differ so dramatically in terms of methodology, that it is not possible to compare them accurately. QoL assessment is carried out using different scales and data are obtained using different tools (for example, self-administered questionnaires, telephone interviews, physician completed questionnaires) in various age and ethnic groups. Nevertheless, regardless of the methods used, there is considerable and uniform agreement in the literature that psoriasis leads to impairment of HRQoL. Moreover, in almost all clinical studies, HRQoL has improved with effective therapy (31). HRQol is also associated with the patient satisfaction of treatment (143).

Of course, factors affecting psoriasis-associated disability may differ from patient to patient. Furthermore, the impact of psoriasis on an individual can vary over time. Population studies, nevertheless, offer a general insight into the factors that affect the QoL of people with psoriasis. 


\section{Chapter 4. Improving the quality of care for people with psoriasis}

\section{Principles of psoriasis management}

Psoriasis is by nature a chronic, incurable disease with an unpredictable course of symptoms and triggers. The consequence is often life-long treatment, therefore, all treatments must meet high quality criteria that are not only efficacious, but also safe over long periods. As the cause of psoriasis is still unknown, treatment is only available to control symptoms. Treatments include a range of topical and systemic therapies as well as phototherapy. It also involves treatment for reducing pain and disability from arthritis and other manifestations.

Care for patients with psoriasis requires more than management of the skin lesions and joint involvement. The complexity of psoriasis means that prescribing drugs in isolation is insufficient to control the disease and a holistic, whole person approach to care is needed. Management of psoriasis also includes screening for associated diseases such as hypertension, dyslipidemia, diabetes mellitus and cardiovascular disorders as well as their complications such as myocardial infarction and stroke (Figure 7). Psoriasis patients are more likely to suffer from depression and anxiety disorders and have an increased rate of suicidal ideation. Screening at regular intervals for these associated diseases and for co-medication to prevent drug-drug interactions or drug-triggered psoriasis as well as recognition of trigger factors and their treatment are an essential part of psoriasis management.

Management algorithms (such as shown in Figure 7) for countries with a developed social and health-care system can be adapted to the needs of local health-care environments. Psychosocial interventions may be needed such as psychological treatment, patient education and psychotherapy $(144,145)$. One-to-one sessions, group therapy, nursing intervention (26) and support by phone or telemedicine (146) may also be helpful. Patient empowerment is a central component of successful programmes (147), as has been demonstrated in other chronic skin diseases (123).

Figure 7. Psoriasis management algorithm

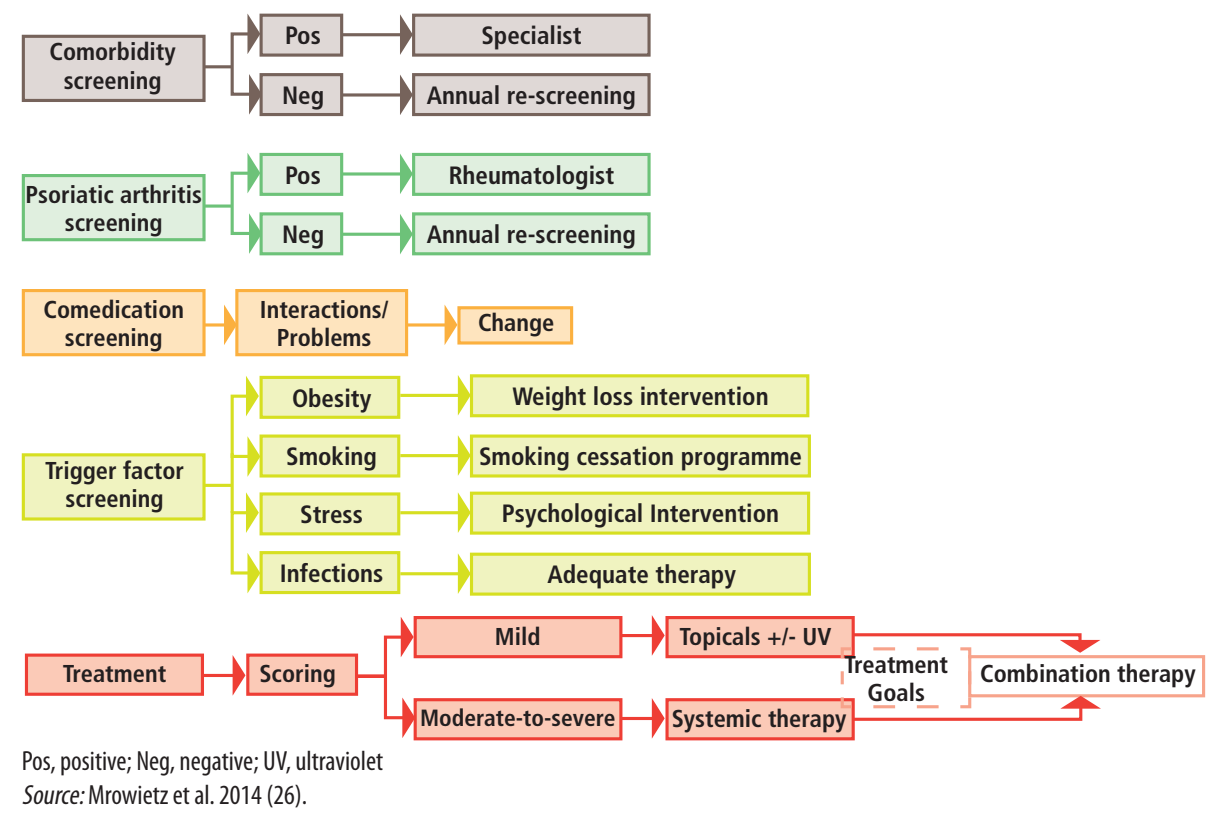




\section{Treating the skin manifestations}

There are three major forms of therapy - topical therapy; phototherapy; and systemic therapy (Table 3). Treatment is based on psoriasis severity at the time of presentation. Mild psoriasis usually is treated with topical therapy, progressing to phototherapy in the case of insufficient response. Moderate to severe psoriasis requires systemic therapy. Commonly used first-line drugs include methotrexate, ciclosporin, acitretin and etretinate. In some countries, other systemic therapies such as biologic agents and fumaric acid esters are available (148). All treatments for psoriasis, apart from retinoids, are primarily anti-inflammatory, and subsequently lead to slowed epidermal keratinocyte turnover and a flattening of plaques. In many countries, other treatments may play a prominent role, including traditional Chinese medicine, self-treatment with over-the-counter products (non-prescription drugs) and climatotherapy.

\section{Table 3. Treatment options for psoriasis}

\begin{tabular}{l|l}
\hline Topical therapies (ointments, creams, & Vitamin $\mathrm{D}_{3}$ analogues \\
\cline { 2 - 2 } lotions, gels, or foams applied to the skin) & Corticosteroids \\
& e.g. betamethasone and hydrocortisone \\
\cline { 2 - 2 } & Anthralin/dithranol \\
\cline { 2 - 2 } & Topical retinoids \\
\hline Phototherapy (UV-light therapy) & Methotrexate \\
\hline Systemic therapies (tablets or \\
injections/infusion) & Ciclosporin \\
\cline { 2 - 2 } & Acitretin \\
\cline { 2 - 2 } & Biologic agents \\
\cline { 2 - 2 } & Oral small molecules \\
\hline
\end{tabular}

The WHO Model List of Essential Medicines (149) includes a small number of topical and systemic treatments that could be useful for patients with psoriasis, which should be considered as a minimum requirement for all health systems (Table 4).

Table 4. Psoriasis treatment options included on the WHO Model List of Essential Medicines

\begin{tabular}{l|l}
\hline \multicolumn{2}{c}{ Core list $^{1}$} \\
\hline Anti-inflammatory and antipruritic medicines & cream or ointment: $0.1 \%$ (as valerate) \\
\hline betamethasone & cream or ointment: $1 \%$ (acetate) \\
\hline hydrocortisone & solution: $5 \%$ \\
\hline Medicines affecting skin differentiation and proliferation \\
\hline coal tar & ointment: $5 \%$ \\
\hline fluorouracil & solution: $5 \%$ \\
\hline salicylic acid & cream or ointment: $5 \% ; 10 \%$ \\
\hline urea & \multicolumn{1}{c}{ Complementary list ${ }^{2}$} \\
\hline Systemic therapies ${ }^{3}$ & tablet: $2.5 \mathrm{mg}$ (as sodium salt) (for joint diseases) \\
\hline methotrexate & capsule: $25 \mathrm{mg}$ (for immunosuppression) \\
\hline ciclosporin &
\end{tabular}

${ }^{1}$ Minimum medicine needs for a basic health-care system.

${ }^{2}$ Medicines for which specialized diagnostic, monitoring, training or care may be needed.

${ }^{3}$ These medicines are not specifically included in the WHO Model List of Essential Medicines for dermatological conditions, but for the indications specified above.

Source: WHO 2015 (149) 
To ensure efficacious and safe treatment, the recommendations of the guidelines for safety monitoring should be followed. Patients - particularly if on newly registered drugs - should have long-term follow-up through enrolment in pharmacovigilance registries. A number of clinical guidelines for the treatment of psoriasis have been developed, including the European psoriasis guidelines and NICE guidelines (150-152).

\section{Treating the whole person: beyond the skin manifestations}

Treating the skin symptoms is not sufficient to control this complex disease, which has unpredictable and varied manifestations and associated diseases.

As outlined in Chapter 3, many people with psoriasis experience psoriatic arthritis thus patients with psoriasis should be screened for the presence of early joint symptoms and if diagnosed with psoriatic arthritis should start appropriate treatment to prevent disease progression and joint destruction. As psoriatic arthritis can develop over time, such screening must be repeated at regular intervals. Several tools have been developed to help detect early signs of psoriatic arthritis (153).

Female, Scotland: "I was diagnosed with scalp psoriasis at age 13 , having to use sticky messy ointments almost every night was bad enough, as a young teenager. ... I was diagnosed with psoriatic arthritis at age 26 .... I was given antiinflammatories, but had continuing flares in my hands, feet, knees, ankles, wrists over many years, swelling and much pain. The attitude then, was 'it won't be serious' - it was and is. ... I now have deformed feet and ankles, and cannot walk far. I have had to have extensive foot surgery."

Source: Psoriasis Scotland Arthritis Link Volunteers.

\section{Understanding triggers}

Several triggering factors have been identified leading to the first manifestation of psoriasis or flares of a stable chronic disease. Understanding and minimizing these triggers can be an important part of managing psoriasis.

In a number of studies from different countries, obesity/weight gain has been identified as a significant trigger for psoriasis (114). Studies have shown that obese psoriasis patients undergoing bariatric surgery with subsequent significant weight loss show improvement of skin lesions (154-156). Obesity is also associated with reduced efficacy of psoriasis treatment $(157,158)$ and is an independent risk factor for cardiovascular disease. Thus, weight loss intervention programmes should be part of psoriasis management.

Tobacco smoking is another important risk factor for psoriasis (114). Counselling for smoking cessation should be included in caregiving. Certain infections can also serve as triggers for psoriasis. Streptococcal throat infection is one important aggravating or initiating factor (159). Periodontitis has also been associated with an increased risk for psoriasis (160). Tonsillectomy in adult patients with recurrent tonsillitis can improve the course of psoriasis and reduce the need for therapy (159). Stress represents a strong aggravating factor for psoriasis in both adults and children, regardless of the nature of the stressor (161).

\section{Barriers to quality care}

Patients suffering from psoriasis face many barriers when dealing with health professionals and health systems. Patients with skin diseases often encounter these barriers, which include a low level of knowledge about skin diseases among non-dermatology trained health professionals, high costs of treatment and limited access to health care. Many low- and middle-income countries have no skin specialists and referral is difficult due to geographic distance and availability of travel funds. There are also barriers specific to 
patients with psoriasis, such as the persistent belief about the alleged contagiousness of the condition, which results from a lack of public awareness and misunderstanding. Adherence to psoriasis treatment is a challenge, and a lack of adherence by many psoriasis patients can be a reason for suboptimal management $(162,163)$.

\section{Inadequate access to health care}

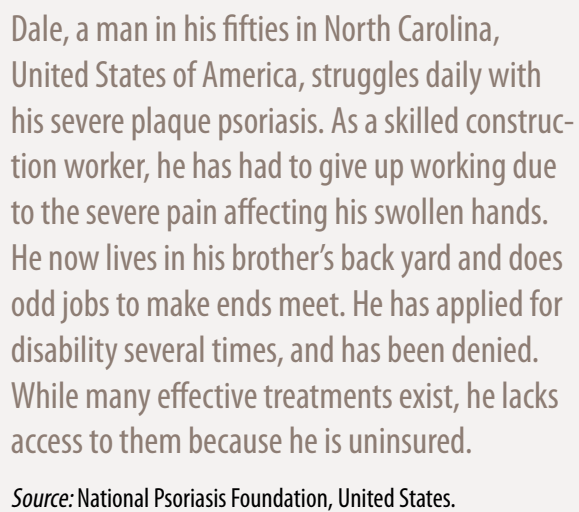

According to the WHO World health statistics 2015, access to health care is still limited in many countries (164). The density of physicians per 10000 population is $\leq 1$ in 21 Member States, and $\leq 10$ in 65 Member States. It should be noted that the data on the density of physicians are not available in 77 Member States, meaning that access to health care could be even lower. Furthermore, the data on access to essential medicines are poor in most low-resource settings.

Another major problem faced by many patients suffering from NCDs, including psoriasis, is inadequate public funding for health care and high out-of-pocket costs. Funds allocated

by many countries for providing basic health care to their citizens are still insufficient. According to the WHO Global health expenditure atlas, a minimum of US\$ 44 is required per person per year to provide basic, life-saving health services (165). According to the World health statistics 2015, 25 WHO Member States spent less than this in 2012 (164).

The above data reflect perfectly a fundamental problem faced by patients suffering from psoriasis. Lack of adequate access to health professionals means no diagnosis, no treatment, uncontrolled development of the disease and disability. Lack of a sufficient number of health professionals to some extent also contributes to low public awareness of psoriasis and the exclusion and discrimination of patients diagnosed with the disease.

\section{Lack of awareness of health professionals}

An insufficient number of health professionals results in a lack of specialist support to general practitioners, who are the lone providers of health care. Lack of adequate training of general practitioners and other health-care providers results in a low awareness of psoriasis (166). Ultimately, lack of awareness about psoriasis and its associated co-morbidities results in under-diagnosis and ineffective therapy, inappropriate to the needs of the patient. The need for increased awareness has been emphasized by the European White Paper on Psoriasis Care (167).

In circumstances where there is limited access to health professionals, the lack of access to medical specialists, including dermatologists, rheumatologists, psychiatrists, cardiologists and paediatricians, is even more likely. In an ideal situation, contact with such specialists is needed to ensure the optimal treatment of psoriasis and prevention and management of attendant co-morbidities. 


\section{Lack of standardized tools for diagnosis and treatment}

Lack of guidelines and tools, which are necessary for a prompt diagnosis of psoriasis and providing appropriate treatment, is another issue faced by patients. It results in unnecessary suffering, uncontrolled disease and irreversible deformities of the joints and disability. Furthermore, patients are often deprived of comprehensive, individually adapted or personalized care. Even in countries where guidelines exists, their uptake is low (167). However, there is evidence that when health-care providers are aware of guidelines and implement them in daily practice, the quality of care for psoriasis patients is increased $(171,172)$.

\section{Cost and availability of essential medicines}

The treatments used for various skin disorders, including psoriasis, can be expensive, life-long and often not financed by universal health coverage schemes. Self-funding of treatment is often ruinous for the patients and their household budget, particularly as many people suffering from psoriasis cannot undertake professional work for health reasons or because of discrimination. According to the WHO Global health expenditure atlas, 100 million people are pushed into poverty every year because they have to pay directly for their health care (165). In many countries, most treatments for psoriasis are either unavailable or are not reimbursed, even those on the WHO Model List of Essential Medicines (166).

Male, South Africa:"I think the main problem that I faced was that the medical aid did not pay for certain treatments, and that became a very costly exercise to get my skin to clear up. This resulted in my family owing the dermatologist a hefty amount of money, because the medical aid stopped funding my treatment (without informing us in time). Eventually, I threw up my hands in despair, and basically, I gave up on my skin treatment. As a result of this, I think about $65-75 \%$ of my body is covered in scales."

Source: South Africa Psoriasis Association.

The prices of psoriasis medications vary considerably - from the relatively inexpensive topical corticosteroids to the more costly biologic therapies (168). Recent advances in biologic agents have considerably expanded the treatment options for patients with psoriasis, however, the prices of these newer treatments are higher than traditional systemic medications and phototherapy $(169,170)$. A cost analysis of systemic therapies conducted between 2000 and 2008 revealed that medication prices are increasing at a rate greater than that of general inflation (170).

Given the chronicity of psoriasis, these expenses compound over the duration of treatment. Whether the cost is born by the patients themselves or by governments and insurance funds, the high cost of therapies for chronic conditions like psoriasis adds a huge burden to overall health expenditure. Manufacturers need to work with purchasers and regulators to provide these therapies at lower prices, especially for newer systemic therapies. Even the costs of generic topical therapies and cheaper systemic treatments such as methotrexate and cyclosporine can be barriers to the optimal management of psoriasis in lower-resource settings (166).

\section{Difficulties with adherence}

Non-adherence to treatment is a barrier to quality care for people with psoriasis. Multiple recurrences, side-effects and cost of treatment can dishearten patients. This can lead to poor adherence to therapy and prevent patients from achieving the best possible results from treatment $(162,163)$. Patient adherence is also negatively associated with dissatisfaction with treatment and psychiatric morbidity (143). Poor adherence is highest with topical therapy, but it is also a problem with systemic treatment that includes biologic agents (30). Low adherence is partly due to insufficient communication regarding instructions on how to use the drug, misperception of possible adverse events and mistaken expectations about the speed and degree of improvement. 


\section{Discrimination}

Discrimination against patients with psoriasis can directly affect their ability to access appropriate health care. In many communities, the belief that psoriasis is contagious can cause problems for patients in public places, including health-care facilities and pharmacies. Exclusion from work reduces the ability to pay for the requisite health care and inhibits full participation in society in a way that promotes their general well-being and a healthy lifestyle. Public misconceptions about psoriasis, for example, the myth that it is a contagious disease, results in exclusion of patients from the everyday life of their communities and fosters low self-esteem, depression and even suicide.

\section{What can be done?}

The negative impact of psoriasis on patients' lives can be reduced in a number of key areas. These include: (i) ensuring that the treatment of skin diseases is included in universal health coverage schemes; (ii) carrying out campaigns and training aimed at increasing knowledge and awareness of psoriasis among health-care providers and society; (iii) increasing research into the etiology of psoriasis; and (iv) developing new therapies targeting the causes of the disease.

\section{Universal access to health services and essential medicines}

The most important step is to implement global commitments to achieve universal health coverage. Universal health coverage has been specifically included in the Sustainable Development Goals for 2030, approved by all United Nations Member States at a High-level Plenary Meeting of the General Assembly in New York on 25-27 September 2015. Member States agreed that they will achieve universal health coverage, including financial risk protection, access to quality essential health-care services and access to safe, effective, quality and affordable essential medicines and vaccines for all by 2030. They also agreed to support research and development of vaccines and medicines for the communicable diseases and NCDs that primarily affect low- and middle-income countries and provide access to medicines for all. Furthermore, they agreed to increase substantially health financing and the recruitment, development, training and retention of the health workforce in low-resource settings, especially in least developed countries and small island developing states.

Meeting the global commitments to provide universal health coverage would have a significant impact on improving the lives of people, especially those with chronic conditions such as psoriasis. Having access to affordable basic health care, having their psoriasis diagnosed and receiving early and appropriate treatment as well as affordable long-term supply of medicines and treatments would significantly reduce the unnecessary burden of psoriasis. Strengthening the health workforce means more general practitioners who have appropriate training in the management of skin diseases.

\section{Patient needs and goals related to treatment}

Globally, there is a high need of psoriasis patients for remission of skin lesions and for relief from the psychosocial burden of disease (139). However, besides the disappearance of visible disease, a variety of other needs were observed, including healing of nonvisible lesions such as in the genital area, relief from itch and pain, more participation in social activities and improvement of functioning in professional and private life (Figure 8). Treatments also should be evaluated for their potential to improve associated conditions. These needs provide hints of the benefits that could be gained from treatment and could thus be used as evaluation criteria for optimizing therapy (173). It is evident that the results of clinical studies 
do not sufficiently reflect the therapeutic benefits from psoriasis treatment since they mostly focus on a few primary and secondary endpoints. Instead, extended outcomes research based on patient-relevant benefit endpoints of psoriasis would better reflect the patients' perspective - that is, patient reported outcomes.

Figure 8. Importance of patient needs related to treatment of psoriasis

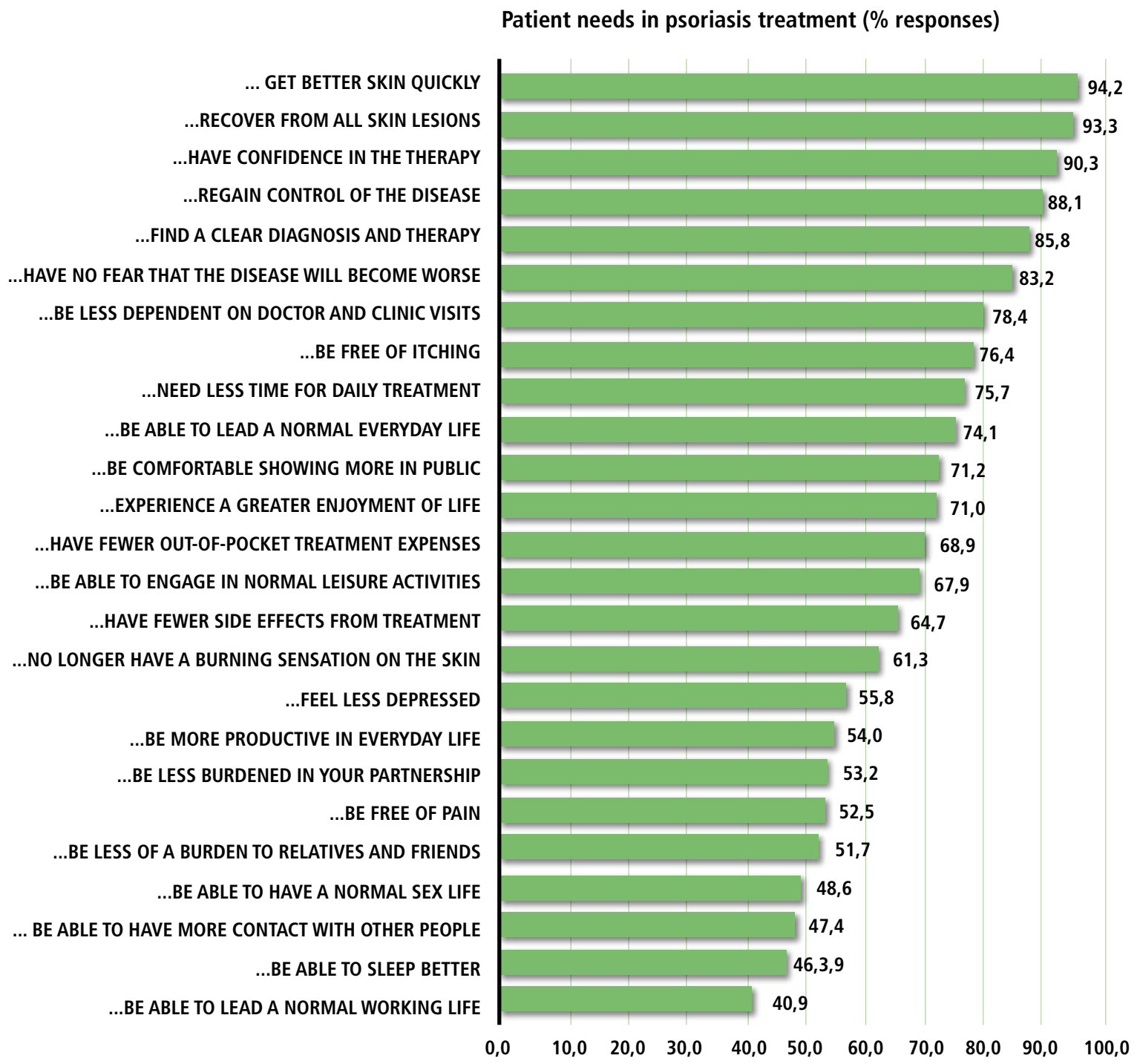

Source: Blome et al. 2011 (139). From German national health-care studies 2007 and 2008 ( $n=4458)$.

\section{A people-centred model of care}

People with chronic and complex conditions, including psoriasis, require a health-care system that responds to their needs as a complete person. This is more difficult to achieve in health systems that are designed for acute episodic care, often for very specific conditions such as maternal and child health, or acute infectious diseases. Health systems in all countries must undergo a fundamental paradigm shift in the model of health-care delivery to respond to the rising burden of chronic complex conditions, and multiple comorbidities, such as psoriasis and other major NCDs.

The WHO global strategy on people-centred and integrated health services is a call for precisely this type of paradigm shift in the way health services are funded, managed and delivered (174). The strategy presents a compelling vision of a future in which all people have access to health services that are provided in a way that responds to their preferences, are coordinated around their needs and are safe, effective, timely, 
efficient and of an acceptable quality. This includes a vision where the services available to people are better able to provide a continuum of care that meets all their health needs, in an integrated way, throughout their life course. People-centred health services are an approach to care that consciously adopts the perspectives of individuals, families and communities, and sees them as participants as well as beneficiaries of trusted health systems that respond to their needs and preferences in humane and holistic ways. It requires that people have the education and support they need to make decisions and participate in their own care. Achieving people-centred and integrated health services can generate significant benefits in all countries, whether low-, middle- or high-income, including conflict afflicted and fragile states, small-island states and large federal states.

For patients with psoriasis, people-centred care could mean that the general practitioner assesses and considers the full spectrum of the person's needs, including the issues related to their psoriasis, but also the other issues related to their health and well-being. The general health-care provider would also have access to refer the patient to a specialist dermatologist for a consultation (or use teledermatology consultations to seek the essential specialist input). The primary care provider, based on consultation with the patient, would seamlessly coordinate the inputs from various specialists, including dermatologists, rheumatologists, cardiologists and psychologists. Furthermore, if a dermatologist is not available, a general practitioner should monitor the progress of treatment, and in the case of relapse refer the patient to the appropriate specialists.

\section{Box 1. Model for improving psoriasis care on a national basis: the German experience}

One example of a large-scale programme to improve health care for psoriasis is the German experience. The approach for improving psoriasis care in Germany started in 2005 with a systematic analysis of the quality, outcomes and potential barriers of health care for psoriasis (172). A series of national health-care studies revealed severe deficits in both the access to modern drugs and the lack of a national guidance, and a large number of patients with high disease severity. Following the development of a psoriasis guideline as a matrix of care in 2006, this was systematically implemented in regional psoriasis networks and evaluated in national trials (172). After making only minor initial improvements, national goals on psoriasis care for 2010-2015 were released in a broad national consensus by dermatology societies, patient groups and decision-makers. These goals are: (i) better QoL for the patients; (ii) earlier detection and better treatment of psoriatic arthritis; (iii) other comorbidity; and (iv) better health care for children with psoriasis.

About 28 regional psoriasis networks were established throughout the country to coordinate high-level health care for psoriasis patients by dermatological experts. In doing so, the latest follow-up data from 2014, which were randomly collected countrywide, revealed significant improvements both on the clinical level of severity and QoL as well as for indirect costs and days of work lost (172). This shows that once health-care providers and patients have reached a consensus, systematic programmes based on standardization, goal orientation and communication at the patient level as well as on the health system level can be successful. This national programme has served as a model for the European Psoriasis White Paper (167) and could be considered by other countries, including for the management of other chronic (skin) diseases.

\section{Standardized tools, diagnosis and treatment}

Health-care providers and dermatologists should use standardized tools to assess the severity of psoriasis and the impact of the disease on QoL. It is important that the medical community reaches a consensus on using a standardized classification of psoriasis and uniform tools for its evaluation. This includes developing standard criteria and guidelines for the diagnosis of psoriasis, which have been developed in a number of countries, including, for example, in the United Kingdom of Great Britain and Northern Ireland (152) and South Africa (176). In addition, guidelines on the treatment of psoriasis are required, including clinical protocols that can be implemented realistically in resource-poor primary care settings. 


\section{Increasing the capacity of the health workforce}

There is a need to increase the skills and capacity of primary health-care providers for psoriasis diagnosis and management. Specialist dermatologists are unavailable for the majority of people living with psoriasis, especially in low- and middle-income countries. The umbrella organizations of health-care providers should take the initiative to conduct education and training for physicians and other health-care providers such as nurses and community health workers in low- and middle-income countries. The development of solutions such as teledermatology also can contribute to faster dermatological diagnosis in countries where there is a lack of skin care specialists. An example of an initiative aimed at training health workers is described in Box 2.

\section{Box 2. Regional Dermatology Training Centre in the United Republic of Tanzania}

One of the institutions that carries out training for physicians from low-resource settings is the International Foundation for Dermatology (IFD), which was created in 1987 as an arm of the International League of Dermatological Societies (ILDS). The IFD established the Regional Dermatology Training Centre (RDTC) in the United Republic of Tanzania and has been training non-doctor skin care providers for the entire continent since 1992.

Source: The International Foundation for Dermatology 2015 (177).

\section{Empowering patients}

Patients' organizations and civil society also have an important role in improving the situation of people with psoriasis. This includes ongoing advocacy on behalf of patients, and government and policy-maker monitoring of the progress of the implementation of resolution WHA67.9 on psoriasis and this report's recommendations. The role of patients' organizations in the creation of peer support groups and social campaigns to increase awareness among society is significant.

For other NCDs, patients' organizations have shown that self-care interventions delivered through community action can be complementary to conventional health care or standalone programmes (175). Community support and family involvement are opportunities to strengthen knowledge and self-efficacy and to build capacity to deliver self-management across a range of chronic diseases.

\section{Combating stigma and discrimination}

Governments must take deliberate steps to combat the important issue of public myths about psoriasis, as many affected individuals around the world experience social and work-related stigmatization and discrimination. This could include conducting an extensive social campaign, aimed at increasing awareness about psoriasis. The use of all available mass media, social media and other means of communication in the local community will aid this purpose. These campaigns should increase public awareness that psoriasis is an NCD, and that it is not a contagious disease. Introducing appropriate legislation to prevent discrimination against people suffering from diseases, such as psoriasis that cause visible body changes, rests with Member States. Boxes 3 and 4 provide examples of campaigns aimed at increasing awareness about psoriasis. 
Box 3. Campaign "Focus on me, not my skin"

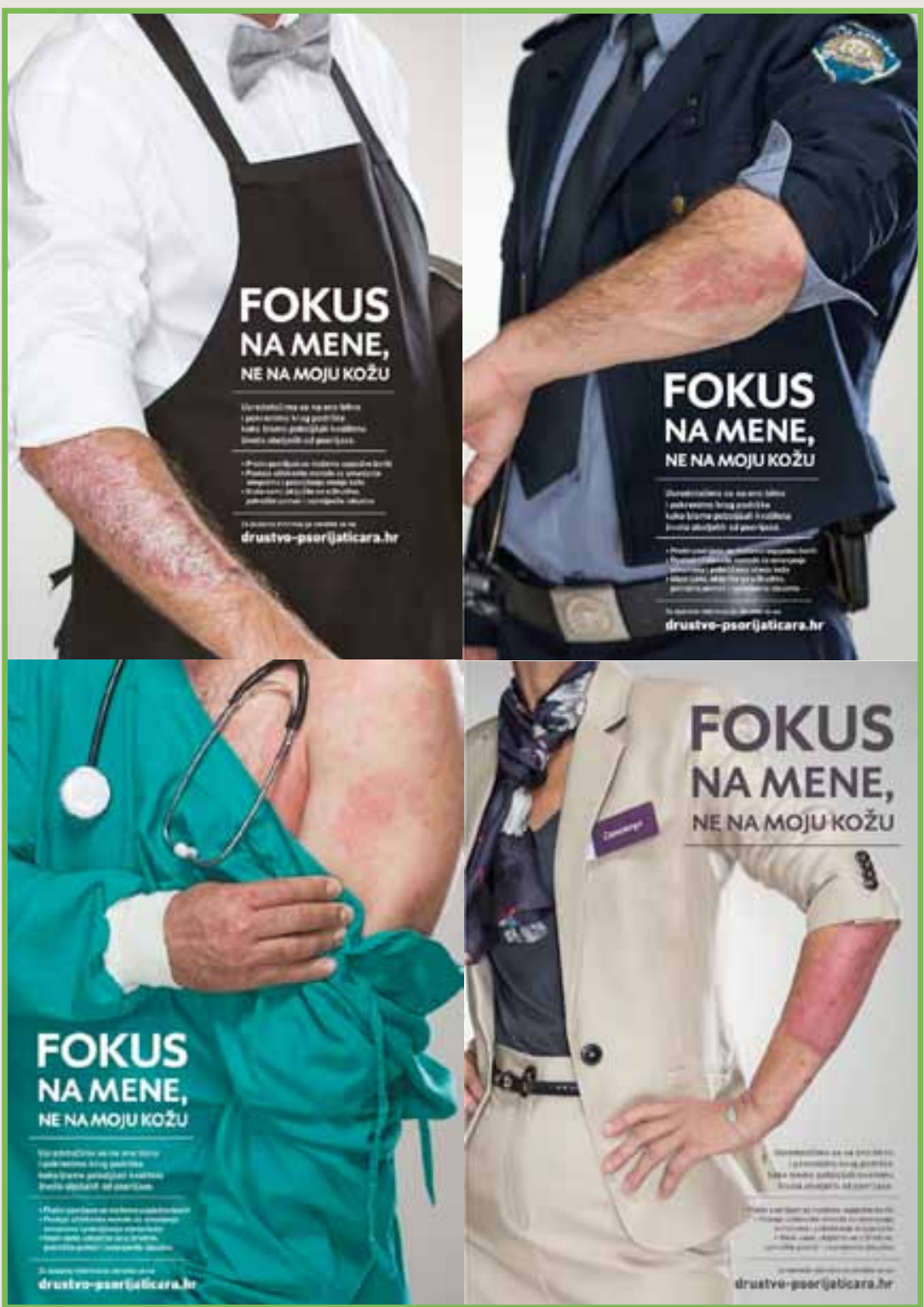

OCroatian Psoriasis Association.

An example of a campaign to address stigma is "Focus on me, not my skin" carried out in 2012 by the Croatian Psoriasis Association. Its purpose was to increase awareness about the everyday challenges of people with psoriasis. 


\section{Box 4. Campaign "Swim for psoriasis"}

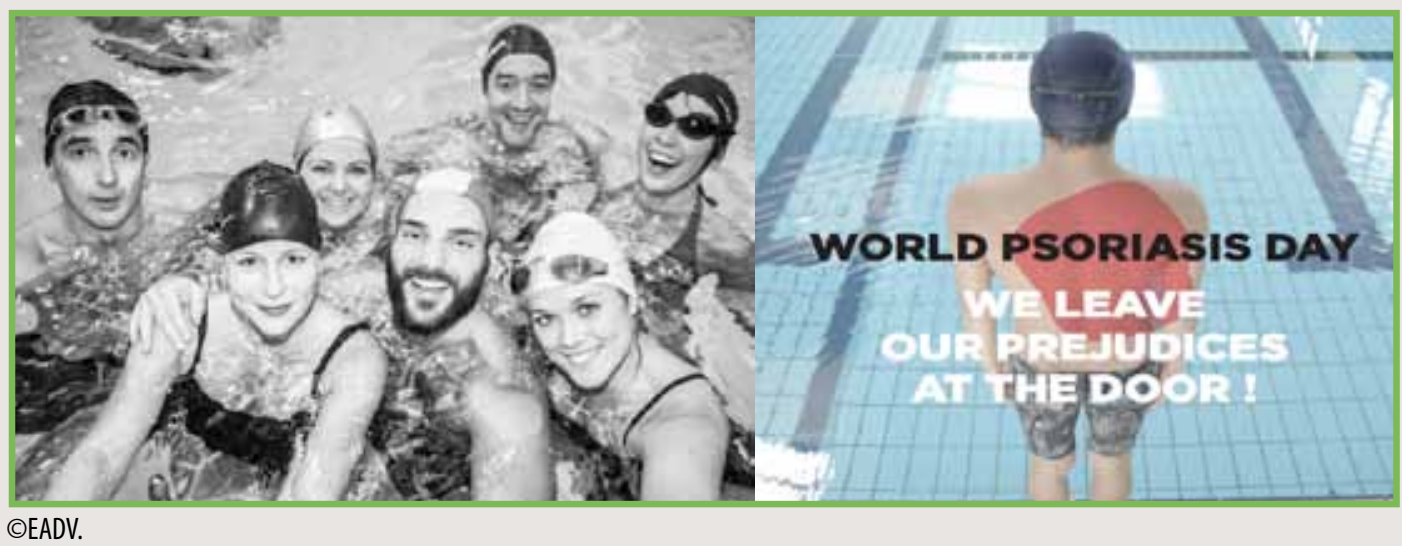

Another example of a campaign for raising awareness of psoriasis is the action "Swim for psoriasis", carried out by the European Academy of Dermatology and Venereology (EADV) in 2014 at the Ixelles swimming pool in Brussels, Belgium. It aimed to fight the prevalent prejudices about psoriasis. Famous Belgians, politicians, dermatologists and patients' associations came together as \#teampsoriasis at the local swimming pool to swim in support of people with psoriasis. 


\section{Chapter 5. Recommendations}

In 2014, WHO Member States recognized psoriasis as a serious NCD in resolution WHA67.9. The resolution underscored that too many people in the world suffer needlessly from psoriasis due to incorrect or delayed diagnosis, inadequate treatment options and insufficient access to care. This Global report on psoriasis brings the public health impact of psoriasis into focus. The report helps raise awareness of the variety of ways that psoriasis can impact people's lives and empowers policy-makers with practical solutions to improve the health care and social inclusion of people in their populations living with this disease.

The control of psoriasis and prevention of its complications require action by governments and policymakers. Furthermore, scientists, health professionals and the associations uniting them have an important role to play in improving the QoL of people suffering from psoriasis. Patients' organizations, civil society and the media are crucial in advocating for change and helping fight stigma and ignorance.

\section{Actions for governments and policy-makers}

- Member States should ensure that people suffering from psoriasis have access to professional medical care. It is essential that psoriasis is diagnosed as early as possible. Early diagnosis and appropriate therapy gives the best chance to prevent patients from unnecessary suffering, uncontrolled disease, irreversible deformities of the joints and disability. Optimum therapy also reduces mental health and societal costs of the disease.

- Patients suffering from psoriasis should have access to comprehensive, individually adapted treatment. At a minimum, public and private facilities should provide the drugs included on the WHO Model List of Essential Medicines, including systemic therapies. Universal health coverage schemes should cover the costs of these treatments For newer biological therapies, more needs to be done to reduce the price of these medicines, if they are to present a sustainable and affordable treatment option for patients with psoriasis. The development of biosimilars may help in this regard. Governments should take cost-effectiveness of treatment options into account when developing national guidelines.

- Optimum treatment of psoriasis, and its comorbidities, require shifting to a model of people-centred and integrated health services, as outlined in the WHO global strategy on people-centred and integrated health services. All people with psoriasis should have access to health services that are provided in a way that responds to their preferences, are coordinated around their needs and are safe, effective, timely, efficient and of an acceptable quality. This is essential not just to improve the lives of people with psoriasis, but also for all other chronic complex conditions.

- Governments and nongovernmental organizations should provideeducation on common chronic skin conditions to health-care professionals, including undergraduate medical and nursing curricula and inservice training for physicians in primary care. There is a great need to raise awareness and knowledge about psoriasis among general practitioners to increase early diagnosis and prevent disability. Governments also have a role in supporting psoriasis research.

- Governments have a key role in reducing stigma and discrimination. Society, not psoriasis, causes the exclusion and discrimination faced by people with this disease. This situation can change through campaigns to raise awareness of psoriasis among the population and by condemning discrimination of patients who suffer from it. Active steps by Member States include anti-discrimination legislation and enforcement of existing legislation. 


\section{Actions for health systems and health professionals}

- All health professionals, especially clinicians working in primary health care, should be aware of psoriasis, its management and its co-morbidities. Health care professionals' associations should provide training, for example, via the Internet for physicians from low- and middle-income countries, regarding prompt diagnosis and effective treatment of psoriasis. Patients with psoriasis need access to primary health care that responds to their individual needs and coordinates with any additional specialist care.

- In settings with adequate resources, health-care professionals and health systems must strive to provide patients with comprehensive care from multidisciplinary teams of specialists, including dermatologists, rheumatologists, psychologists, psychiatrists, paediatricians, cardiologists and others. Clinicians must inform patients about the possible consequences of the disease and collaborate with them to identify barriers to adherence and help address these barriers to achieve optimal management.

- Associations of medical specialists have a role in seeking consensus on the classification of psoriasis and standardization of the collection of epidemiological data using a unified methodology.

- There is a great need to develop guidelines regarding the diagnosis of psoriasis and its treatment. Furthermore, certain standards relating to medical care such as adequate assessment of progress of therapy, using uniform tools to assess the severity of the disease and patient QoL should be implemented. Doctors should establish objectives of care and plan therapy in collaboration with their patients.

\section{Actions for patients' organizations and civil society}

- Patients' organizations must continue advocating for the rights of individuals suffering from psoriasis. They should be involved in raising awareness of psoriasis among the population in collaboration with governments and policy-makers.

- Patients' organizations have a key role in providing support to people suffering from psoriasis and in creating networks to foster mutual support and exchange of experiences.

- Patients' organizations have a responsibility to encourage the formation of patients' associations where currently none exists.

- Patients' organizations and civil society have a key role in holding governments and policy-makers to account on global commitments, and in fighting discrimination of people with psoriasis.

\section{Priority areas for research}

- There are many unmet needs for psoriasis, including epidemiology, etiology, treatment and ways to improve health care. Researchers should investigate the etiology of psoriasis and therapies to prevent as well as to manage the symptoms of the disease. It is vital to create low-cost effective treatment options that can be made widely available.

- Research on new treatments should focus on options which can be applicable globally, on a large scale. New treatments need to be affordable, effective and safe in the long term, stable in hot and humid climates and require minimal monitoring.

- Prospective, controlled studies are needed to further clarify the association between psoriasis and cardiovascular disorders on a pathogenic level and to substantiate the beneficial effect of treatment for skin/joints and associated disorders. 
- In clinical research, there is a need for comparative effectiveness research in order to identify the benefits and efficiency of treatments.

- For research outcomes that are more reliable, the currently used clinical outcome parameters, including PASI and patient-reported outcomes such as DLQI, need to be improved.

- Health services research needs to be better used in identifying specific needs of health care, unmet patient needs and barriers of guideline-compliant treatment. Health services research should monitor and provide feedback on the actions taken to improve quality of care and investigate efficiency of care. Psoriasis care could thus become a model for the management of other chronic (skin) diseases.

- A key area of health-care research is the epidemiology of psoriasis and its incidence and prevalence on the global level. Research methods need to be harmonized and reflect cultural as well as geographical differences. 


\section{References}

1. Institute for Health Metrics and Evaluation (IHME). Global Burden of Disease Study 2010: Results by Cause 1990-2010. Seattle: IHME; 2012.

2. Gibbs S. Skin disease and socioeconomic conditions in rural Africa: Tanzania. Int J Dermatol. 1996;35(9):633-9.

3. Danielsen $\mathrm{K}$, Olsen AO, Wilsgaard T, Furberg AS. Is the prevalence of psoriasis increasing? A 30-year follow-up of a population-based cohort. Br J Dermatol. 2013;168:1303-10.

4. Harden JL, Krueger JG, Bowcock AM. The immunogenetics of psoriasis: a comprehensive review. J Autoimmun. 2015;64:66-73.

5. Boehncke W-H, Schön MP. Psoriasis. Lancet. 2015;386(9997):983-94.

6. Bedi TR. Clinical profile of psoriasis in North India. Indian J Dermatol Venereol Leprol. 1995;61(4):202-5.

7. Pariser D, Schenkel B, Carter C, Farahi K, Brown TM, Ellis CN, and Psoriasis Patient Interview Study Group. A multicenter, non-interventional study to evaluate patient-reported experiences of living with psoriasis. J Dermatol Treat. 2015;1-8.

8. Alshami MA. Clinical profile of psoriasis in Yemen, a 4-year retrospective study of 241 patients. J Eur Acad Dermatol Venereol. 2010;24(Suppl. 4):14.

9. Falodun OA. Characteristics of patients with psoriasis seen at the dermatology clinic of a tertiary hospital in Nigeria: a 4-year review 2008-2012. J Eur Acad Dermatol Venereol. 2013;27(Suppl. 4)

10. Reich K, Krüger K, Mössner R, Augustin M. Epidemiology and clinical pattern of psoriatic arthritis in Germany: a prospective interdisciplinary epidemiological study of 1511 patients with plaque-type psoriasis. Br J Dermatol. 2009;160(5):1040-7.

11. Augustin M, Radtke MA, Glaeske G, Reich K, Christophers E, Schaefer I et al. Epidemiology and Comorbidity in Children with Psoriasis and Atopic Eczema. Dermatology. 2015;231(1):35-40.

12. Vena GA, Altomare G, Ayala F, Berardesca E, Calzavara-Pinton P, Chimenti S et al. Incidence of psoriasis and association with comorbidities in Italy: a 5-year observational study from a national primary care database. Eur J Dermatol. 2010;20(5):593-8.

13. Fuji R, Mould JF J, Tang B, Brandt H, Pomerantz D, Chapnick J et al. Burden of disease in patients with diagnosed psoriasis in Brazil: results from 2011 national health and wellness survey (NHWS). Value Health. 2012;15(4):A107.

14. Stern RS, Nijsten T, Feldman SR, Margolis DJ, Rolstad T. Psoriasis is common, carries a substantial burden even when not extensive, and is associated with widespread treatment dissatisfaction. J Investig Dermatol Symp Proc. 2004;9(2):136-9.

15. Kimball AB, Jacobson C, Weiss S, Vreeland MG, Wu Y. The psychosocial burden of psoriasis. Am J Clin Dermatol. 2005;6(6):383-92.

16. De Korte J, Sprangers MA, Mombers FM, Bos JD. Quality of life in patients with psoriasis: a systematic literature review. J Investig Dermatol Symp Proc. 2004;9(2):140-7.

17. Zachariae H, Zachariae R, Blomqvist K, Davidsson S, Molin L, Mørk C et al. Quality of life and prevalence of arthritis reported by 5,795 members of the Nordic Psoriasis Associations. Data from the Nordic Quality of Life Study. Acta Derm Venereol. 2002;82(2):108-13.

18. Krueger G, Koo J, Lebwohl M, Menter A, Stern RS, Rolstad T. The impact of psoriasis on quality of life: results of a 1998 National Psoriasis Foundation patient-membership survey. Arch Dermatol. 2001;137(3):280-4.

19. Weiss SC, Kimball AB, Liewehr DJ, Blauvelt A, Turner ML, Emanuel EJ. Quantifying the harmful effect of psoriasis on health-related quality of life. J Am Acad Dermatol. 2002;47(4):512-8. 
20. Kimball AB, Gieler U, Linder D, Sampogna F, Warren RB, Augustin M. Psoriasis: Is the impairment to a patient's life cumulative? J Eur Acad Dermatol Venereol. 2010;24(9):989-1004.

21. Moradi M, Rencz F, Brodszky V, Moradi A, Balogh O, Gulácsi L. Health status and quality of life in patients with psoriasis: an Iranian cross-sectional survey. Arch Iran Med. 2015;18(3):153-9.

22. Tang MM, Chang CC, Chan LC, Heng A. Quality of life and cost of illness in patients with psoriasis in Malaysia: a multicenter study. Int J Dermatol. 2013;52(3):314-22.

23. Augustin M, Krüger K, Radtke MA, Schwippl I, Reich K. Disease severity, quality of life and health care in plaquetype psoriasis: a multicenter cross-sectional study in Germany. Dermatology. 2008;216(4):366-72.

24. Russo PAJ, Ilchef R, Cooper AJ. Psychiatric morbidity in psoriasis: a review. Australas J Dermatol. 2004;45(3):1559; quiz;160-1.

25. Sampogna F, Tabolli S, Abeni D, IDI Multipurpose Psoriasis Research on Vital Experiences (IMPROVE) investigators. Living with psoriasis: prevalence of shame, anger, worry, and problems in daily activities and social life. Acta Derm Venereol. 2012;92(3):299-303.

26. Mrowietz U, Steinz K, Gerdes S. Psoriasis: To treat or to manage? Exp Dermatol. 2014;23(10):705-9.

27. Parisi R, Symmons DPM, Griffiths CEM, Ashcroft DM, and the Identification and Management of Psoriasis and Associated ComorbidiTy (IMPACT) project team. Global epidemiology of psoriasis: a systematic review of incidence and prevalence. J Invest Dermatol. 2013;133(2):377-85.

28. Gelfand JM, Feldman SR, Stern RS, Thomas J, Rolstad T, Margolis DJ. Determinants of quality of life in patients with psoriasis: a study from the US population. J Am Acad Dermatol. 2004;51(5):704-8.

29. Nijsten T, Meads DM, de Korte J, Sampogna F, Gelfand JM, Ongenae K et al. Cross-cultural inequivalence of dermatology-specific health-related quality of life instruments in psoriasis patients. J Invest Dermatol. 2007;127(10):2315-22.

30. Augustin M, Radtke MA. Quality of life in psoriasis patients. Expert Rev Pharmacoecon Outcomes Res. 2014;14(4):559-68.

31. Prins M, Krabbe PFM, Swinkels QOJ, de Boo T, van de Kerkhof PCM, van der Valk PGM. The effect of treatment on quality of life in psoriasis patients. Acta Derm Venereol. 2005;85(4):304-10.

32. Vardy D, Besser A, Amir M, Gesthalter B, Biton A, Buskila D. Experiences of stigmatization play a role in mediating the impact of disease severity on quality of life in psoriasis patients. Br J Dermatol. 2002;147(4):736-42.

33. Bell LM, Sedlack R, Beard CM, Perry HO, Michet CJ, Kurland LT. Incidence of psoriasis in Rochester, Minn, 19801983. Arch Dermatol. 1991;127(8):1184-7.

34. Ammar-Khodja A, Benkaidali I, Bouadjar B, Serradj A, Titi A, Benchikhi H et al. EPIMAG: International CrossSectional Epidemiological Psoriasis Study in the Maghreb. Dermatology. 2015;231(2):134-44.

35. Jacobson CC, Kumar S, Kimball AB. Latitude and psoriasis prevalence. J Am Acad Dermatol. 2011;65(4):870-3.

36. Bø K, Thoresen M, Dalgard F. Smokers report more psoriasis, but not atopic dermatitis or hand eczema: results from a Norwegian population survey among adults. Dermatol Basel Switz. 2008;216(1):40-5.

37. Shao CG, Zhang GW, Wang GC. Distribution of psoriasis in China: a nationwide screening. Proc Chin Acad Med Sci Peking Union Med Coll. 1987;2(2):59-65.

38. Chen G-Y, Cheng Y-W, Wang C-Y, Hsu T-J, Hsu MM-L, Yang P-T et al. Prevalence of skin diseases among schoolchildren in Magong, Penghu, Taiwan: a community-based clinical survey. J Formos Med Assoc. 2008;107(1):21-9.

39. Yang Y-C, Cheng Y-W, Lai C-S, Chen W. Prevalence of childhood acne, ephelides, warts, atopic dermatitis, psoriasis, alopecia areata and keloid in Kaohsiung County, Taiwan: a community-based clinical survey. J Eur Acad Dermatol Venereol. 2007;21(5):643-9.

40. Li M-J, Wang P, Wu W-W, Fu L, Cai M, Chen M-X et al. An epidemiological survey of psoriasis in 18 cities in Hainan province of China. J Dermatol. 2012;39(Suppl. 1):243-4. 
41. Chang Y-T, Chen T-J, Liu P-C, Chen Y-C, Chen Y-J, Huang Y-L et al. Epidemiological study of psoriasis in the national health insurance database in Taiwan. Acta Derm Venereol. 2009;89(3):262-6.

42. Yip SY. The prevalence of psoriasis in the Mongoloid race. J Am Acad Dermatol. 1984;10(6):965-8.

43. Ding $X$, Wang T, Shen $Y$, Wang $X$, Zhou C, Tian $S$ et al. Prevalence of psoriasis in China: a population-based study in six cities. Eur J Dermatol. 2012;22(5):663-7.

44. Wang R, Cao L, Zhou C, Zhang J. Prevalence of 15 skin diseases in adolescents from Liangshan prefecture in Sichuan Province. Chin J Dermatol. 2012;45(4):270-2.

45. Kubota K, Kamijima Y, Sato T, Ooba N, Koide D, lizuka H et al. Epidemiology of psoriasis and palmoplantar pustulosis: a nationwide study using the Japanese national claims database. BMJ Open. 2015;5(1):e006450.

46. Rachakonda TD, Schupp CW, Armstrong AW. Psoriasis prevalence among adults in the United States. J Am Acad Dermatol. 2014;70(3):512-6.

47. Yamamah GA, Emam HM, Abdelhamid MF, Elsaie ML, Shehata H, Farid T et al. Epidemiologic study of dermatologic disorders among children in South Sinai, Egypt. Int J Dermatol. 2012;51(10):1180-5.

48. El-Khateeb EA, Lotfi RA, Abd Elaziz KM, Abdel-Aziz KM, El-Shiekh SE. Prevalences of skin diseases among primary schoolchildren in Damietta, Egypt. Int J Dermatol. 2014;53(5):609-16.

49. Augustin M, Glaeske G, Radtke M, Christophers E, Reich K, Schaefer I. Epidemiology and comorbidity of psoriasis in children. Br J Dermatol. 2010;162:633-6.

50. Matusiewicz D, Koerber A, Schadendorf D, Wasem J, Neumann A. Childhood psoriasis: an analysis of German health insurance data. Pediatr Dermatol. 2014;31(1):8-13.

51. Kampfe S, Augustin M, Schäfer I, Glaeske G, Schicktanz C, Radtke M. Prevalence and health care situation of juvenile psoriasis in Germany. Exp Dermatol. 2012;21(3):e21.

52. Schmitt J, Apfelbacher C. Epidemiology of pediatric psoriasis: a representative German cross-sectional study. Exp Dermatol. 2010;19(2):219.

53. Cantarutti A, Donà D, Visentin F, Borgia E, Scamarcia A, Cantarutti L et al., and the Pedianet. Epidemiology of Frequently Occurring Skin Diseases in Italian Children from 2006 to 2012: a retrospective population-based study. Pediatr Dermatol. 2015;32(5):668-78.

54. Cantarutti A, Donà D, Visentin F, Borgia E, Scamarcia A, Cantarutti L et al., and the Pedianet. Epidemiology of Frequently Occurring Skin Diseases in Italian Children from 2006 to 2012: a retrospective population-based study. Pediatr Dermatol. 2015 Sep;32(5):668-78.

55. Larsson PA, Lidén S. Prevalence of skin diseases among adolescents 12-16 years of age. Acta Derm Venereol. 1980;60(5):415-23.

56. Quirk CJ. Skin disease in the Busselton population survey. Med J Aust. 1979;1(12):569-70.

57. Kilkenny M, Stathakis V, Jolley D, Marks R. Maryborough skin health survey: prevalence and sources of advice for skin conditions. Australas J Dermatol. 1998;39(4):233-7.

58. Plunkett A, Marks R. A review of the epidemiology of psoriasis vulgaris in the community. Australas J Dermatol. 1998;39(4):225-32.

59. Barisic-Drusko V, Paljan D, Kansky A, Vujasinovic S. Prevalence of Psoriasis in Croatia. Acta Derm Venereol Suppl (Stockh). 1989;146:178-9.

60. Brandrup F, Green A. The prevalence of psoriasis in Denmark. Acta Derm Venereol. 1981;61:344-6.

61. Wolkenstein P, Revuz J, Roujeau JC, Bonnelye G, Grob JJ, Bastuji-Garin S, and the French Society of Dermatology. Psoriasis in France and associated risk factors: results of a case-control study based on a large community survey. Dermatol Basel Switz. 2009;218(2):103-9.

62. Augustin M, Herberger K, Hintzen S, Heigel H, Franzke N, Schäfer I. Prevalence of skin lesions and need for treatment in a cohort of 90880 workers. Br J Dermatol. 2011;165(4):865-73.

63. Schaefer I, Rustenbach SJ, Zimmer L, Augustin M. Prevalence of skin diseases in a cohort of 48,665 employees in Germany. Dermatology. 2008;217(2):169-72. 
64. Naldi L, Colombo P, Placchesi EB, Piccitto R, Chatenoud L, La Vecchia C, PraKtis Study Centers. Study design and preliminary results from the pilot phase of the PraKtis study: self-reported diagnoses of selected skin diseases in a representative sample of the Italian population. Dermatology. 2004;208(1):38-42.

65. Kavli G, Forde $\mathrm{OH}$, Arnesen E, Stenvold SE. Psoriasis: familial predisposition and environmental factors. Br Med J. 1985;291:999-1000.

66. Olsen AO, Grjibovski A, Magnus P, Tambs K, Harris JR. Psoriasis in Norway as observed in a population-based Norwegian twin panel. Br J Dermatol. 2005;153(2):346-51.

67. Lindberg M, Isacson D, Bingefors K. Self-reported skin diseases, quality of life and medication use: a nationwide pharmaco-epidemiological survey in Sweden. Acta Derm Venereol. 2014;94(2):188-91.

68. O'Neill P, Kelly P. Postal questionnaire study of disability in the community associated with psoriasis. BMJ. 1996;313(7062):919-21.

69. Kurd SK, Gelfand JM. The prevalence of previously diagnosed and undiagnosed psoriasis in US adults: results from NHANES 2003-2004. J Am Acad Dermatol. 2009;60(2):218-24.

70. Merola J, Li T, Qureshi A. Prevalence of psoriasis phenotypic subsets among US men and women. J Invest Dermatol. 134(Suppl. 1):S58.

71. Takeshita J, Gelfand JM, Li P, Pinto L, Yu X, Rao P et al. Psoriasis in the US Medicare population: prevalence, treatment, and factors associated with biologic use. J Invest Dermatol. 2015;135(12):2955-63.

72. Helmick CG, Lee-Han H, Hirsch SC, Baird TL, Bartlett CL. Prevalence of psoriasis among adults in the U.S.: 20032006 and 2009-2010 National Health and Nutrition Examination Surveys. Am J Prev Med. 2014;47(1):37-45.

73. Gelfand JM, Stern RS, Nijsten T, Feldman SR, Thomas J, Kist J et al. The prevalence of psoriasis in African Americans: results from a population-based study. J Am Acad Dermatol. 2005;52(1):23-6.

74. Robinson D, Hackett M, Wong J, Kimball AB, Cohen R, Bala M, and the IMID Study Group. Co-occurrence and comorbidities in patients with immune-mediated inflammatory disorders: an exploration using US healthcare claims data, 2001-2002. Curr Med Res Opin. 2006;22(5):989-1000.

75. Qureshi AA, Choi HK, Setty AR, Curhan GC. Psoriasis and the risk of diabetes and hypertension: a prospective study of US female nurses. Arch Dermatol. 2009;145(4):379-82.

76. Tsai T-F, Wang T-S, Hung S-T, Tsai PI-C, Schenkel B, Zhang M et al. Epidemiology and comorbidities of psoriasis patients in a national database in Taiwan. J Dermatol Sci. 2011;63(1):40-6.

77. Lomholt G. A census study on the prevalence of skin diseases in the Faroe Islands. Cpenhagen: GEC Gad; 1963.

78. Abdel-Hafez K, Abdel-Aty MA, Hofny ERM. Prevalence of skin diseases in rural areas of Assiut Governorate, Upper Egypt. Int J Dermatol. 2003;42(11):887-92.

79. Schaefer I, Rustenbach S, Radtke M, Augustin J, Glaeske G, Augustin M. Epidemiologie der Psoriasis in Deutschland - Auswertung von Sekundärdaten einer gesetzlichen Krankenversicherung. Gesundheitswesen. 2011;73(5):308-13.

80. Schlander M, Schwarz O, Viapiano M, Bonauer N. Administrative prevalence of psoriasis in Germany. Value Health. 2008;11(6):A615-6.

81. Saraceno R, Mannheimer R, Chimenti S. Regional distribution of psoriasis in Italy. J Eur Acad Dermatol Venereol. 2008;22(3):324-9.

82. Braathen LR, Botten G, Bjerkedal T. Psoriatics in Norway. A questionnaire study on health status, contact with paramedical professions, and alcohol and tobacco consumption. Acta Derm Venereol Suppl (Stockh). 1989;142:9-12.

83. Falk ES, Vandbakk O. Prevalence of psoriasis in a Norwegian Lapp population. Acta Derm Venereol Suppl (Stockh). 1993;182:6-9.

84. Borzęcki A, Dudra-Jastrzębska M, Sajdak-Wojtaluk A. Epidemiologia łuszczycy w rejonie województwa lubelskiego w latach 2005-2009. Dermatol Klin. 2012;14(4):149-53.

85. Massa A, Alves R, Amado J, Matos E, Sanches M, Selores $M$ et al. Prevalence of cutaneous lesions in Freixo de Espada à Cinta. Acta Médica Port. 2000;13(5-6):247-54. 
86. Ferrándiz C, Bordas X, García-Patos V, Puig S, Pujol R, Smandía A. Prevalence of psoriasis in Spain (Epiderma Project: phase I). J Eur Acad Dermatol Venereol. 2001;15(1):20-3.

87. Ferrándiz C, Carrascosa JM, Toro M. Prevalence of psoriasis in Spain in the age of biologics. Actas DermoSifiliográficas. 2014;105(5):504-9.

88. Perera A, Atukorale DN, Sivayogan S, Ariyaratne VS, Karunaratne LA. Prevalence of skin diseases in suburban Sri Lanka. Ceylon Med J. 2000;45(3):123-8.

89. Lofvendahl S, Theander E, Svensson A, Englund M, Turkiewicz A, Petersson I. The prevalence of psoriasis and psoriatic arthritis in Sweden a health care register study. Arthritis Rheum. 2009;60(Suppl. 10):710.

90. Lofvendahl S, Theander E, Svensson A, Englund M, Turkiewicz A, Petersson I. Prevalence of doctordiagnosed psoriasis and psoriatic arthritis in southern Sweden. Br J Dermatol. 2012;167(2):e11.

91. El Fekih N, Khaled A, Kharafi M, Sellami A, Zeglaoui F, Fazaa B et al. Epidemiology of psoriasis in Tunisia. J Eur Acad Dermatol Venereol. 2007;(Suppl. 1):41.

92. Seminara NM, Abuabara K, Shin DB, Langan SM, Kimmel SE, Margolis D et al. Validity of The Health Improvement Network (THIN) for the study of psoriasis. Br J Dermatol. 2011;164(3):602-9.

93. Nevitt GJ, Hutchinson PE. Psoriasis in the community: prevalence, severity and patients' beliefs and attitudes towards the disease. Br J Dermatol. 1996;135(4):533-7.

94. Gelfand JM, Weinstein R, Porter SB, Neimann AL, Berlin JA, Margolis DJ. Prevalence and treatment of psoriasis in the United Kingdom: a population-based study. Arch Dermatol. 2005;141(12):1537-41.

95. Kay L, Parry-James J, Walker D. The prevalence and impact of psoriasis and psoriatic arthritis in the primary care population in North East England. Arthritis Rheum. 1999;42(9):S299-S299.

96. Gillard SE, Finlay AY. Current management of psoriasis in the United Kingdom: patterns of prescribing and resource use in primary care. Int J Clin Pract. 2005;59(11):1260-7.

97. Simpson CR, Anderson WJA, Helms PJ, Taylor MW, Watson L, Prescott GJ et al. Coincidence of immunemediated diseases driven by Th1 and Th2 subsets suggests a common aetiology. A population-based study using computerized general practice data. Clin Exp Allergy J Br Soc Allergy Clin Immunol. 2002;32(1):37-42.

98. Johnson MT, Roberts J. Skin conditions and related need for medical care among persons 1-74-year. United States, 1971-1974. Vital Health Stat 11. 1978;(212):1-72.

99. Lima XT, Minnillo R, Spencer JM, Kimball AB. Psoriasis prevalence among the 2009 AAD National Melanoma/Skin Cancer Screening Program participants. J Eur Acad Dermatol Venereol. 2013;27(6):680-5.

100. Henseler T, Christophers E. Psoriasis of early and late onset: characterization of two types of psoriasis vulgaris. J Am Acad Dermatol. 1985;13(3):450-6.

101. Goff KL, Karimkhani C, Boyers LN, Weinstock MA, Lott JP, Hay RJ et al. The global burden of psoriatic skin disease. Br J Dermatol. 2015;172(6):1665-8.

102. Hay RJ, Johns NE, Williams HC, Bolliger IW, Dellavalle RP, Margolis DJ et al. The global burden of skin disease in 2010: an analysis of the prevalence and impact of skin conditions. J Invest Dermatol. 2014;134(6):1527-34.

103. Abuabara K, Azfar RS, Shin DB, Neimann AL, Troxel AB, Gelfand JM. Cause-specific mortality in patients with severe psoriasis: a population-based cohort study in the U.K. Br J Dermatol. 2010;163(3):586-92.

104. Naldi L, Svensson A, Diepgen T, Elsner P, Grob J-J, Coenraads P-J et al., and the European DermatoEpidemiology Network. Randomized clinical trials for psoriasis 1977-2000: the EDEN survey. J Invest Dermatol. 2003;120(5):738-41.

105. Dubertret L, Mrowietz U, Ranki A, van de Kerkhof PC, Chimenti S Lotti T et al. European patient perspectives on the impact of psoriasis: the EUROPSO patient membership survey. Br J Dermatol. 155(4):729-36.

106. Owen CM, Chalmers RJ, O'Sullivan T, Griffiths CE. Antistreptococcal interventions for guttate and chronic plaque psoriasis. Cochrane Database Syst Rev. 2000;(2):CD001976.

107. Natarajan V, Nath AK, Thappa DM, Singh R, Verma SK. Coexistence of onychomycosis in psoriatic nails: a descriptive study. Indian J Dermatol Venereol Leprol. 2010;76(6):723. 
108. Augustin M, Reich K, Blome C, Schäfer I, Laass A, Radtke MA. Nail psoriasis in Germany: epidemiology and burden of disease. Br J Dermatol. 2010;163(3):580-5.

109. Kerr GS, Qaiyumi S, Richards J, Vahabzadeh-Monshie H, Kindred C, Whelton S et al. Psoriasis and psoriatic arthritis in African-American patients: the need to measure disease burden. Clin Rheumatol. 2014.

110. Radtke MA, Reich K, Blome C, Rustenbach S, Augustin M. Prevalence and clinical features of psoriatic arthritis and joint complaints in 2009 patients with psoriasis: results of a German national survey. J Eur Acad Dermatol Venereol. 2009;23(6):683-91.

111. Shaharyar S, Warraich H, McEvoy JW, Oni E, Ali SS, Karim A et al. Subclinical cardiovascular disease in plaque psoriasis: association or causal link? Atherosclerosis. 2014;232(1):72-8.

112. Robati RM, Partovi-Kia M, Haghighatkhah HR, Younespour S, Abdollahimajd F. Increased serum leptin and resistin levels and increased carotid intima-media wall thickness in patients with psoriasis: is psoriasis associated with atherosclerosis? J Am Acad Dermatol. 2014;71(4):642-8.

113. Ahlehoff $\mathrm{O}$, Gislason $\mathrm{GH}$, Jørgensen $\mathrm{CH}$, Lindhardsen J, Charlot M, Olesen JB et al. Psoriasis and risk of atrial fibrillation and ischaemic stroke: a Danish Nationwide Cohort Study. Eur Heart J. 2012;33(16):2054-64.

114. Wolk K, Mallbris L, Larsson P, Rosenblad A, Vingård E, Ståhle M. Excessive body weight and smoking associates with a high risk of onset of plaque psoriasis. Acta Derm Venereol. 2009;89(5):492-7.

115. Tasliyurt T, Bilir Y, Sahin S, Seckin HY, Kaya SU, Sivgin H et al. Erectile dysfunction in patients with psoriasis: potential impact of the metabolic syndrome. Eur Rev Med Pharmacol Sci. 2014;18(4):581-6.

116. Van der Voort EAM, Koehler EM, Dowlatshahi EA, Hofman A, Stricker BH, Janssen HLA et al. Psoriasis is independently associated with nonalcoholic fatty liver disease in patients 55 years old or older: Results from a population-based study. J Am Acad Dermatol. 2014;70(3):517-24.

117. Nijsten T, Wakkee M. Complexity of the association between psoriasis and comorbidities. J Invest Dermatol. 2009;129(7):1601-3.

118. Parisi R, Rutter MK, Lunt M, Young HS, Symmons DPM, Griffiths CEM et al. Psoriasis and the Risk of Major Cardiovascular Events: cohort study using the Clinical Practice Research Datalink. J Invest Dermatol. 2015;135(9):2189-97.

119. Gupta MA, Schork NJ, Gupta AK, Kirkby S, Ellis CN. Suicidal ideation in psoriasis. Int J Dermatol. 1993;32(3):18890.

120. Mahler V, Diepgen T, Skudlik C, Becker D, Dickel H, Fartasch M et al., and the Work Group "Assessment of allergens in occupational disease (BK) 5101" of the Study Group Occupational and Environmental Dermatology $(A B D)$, German Contact Dermatitis Group (DKG) of the German Dermatological Society. Psoriasis predisposition and occupational triggering factors in the appraisal of occupational medical expertises. J Dtsch Dermatol Ges. 2014;12(6):519-29.

121. Skudlik C, John SM. Psoriasis and work. In: Kanerva's Occupational dermatology, 2nd edition (volume 1). Heidelberg, New York, Dordrecht, London: Springer; 2012.

122. Agrup G. Hand Eczema and Other Hand Dermatoses in South Sweden. J Occup Environ Med. 1970;12(2):59-60.

123. Weisshaar E, Skudlik C, Scheidt R, Matterne U, Wulfhorst B, Schönfeld M et al., and the ROQ Study Group. Multicentre study "rehabilitation of occupational skin diseases: optimization and quality assurance of inpatient management (ROQ)"- results from 12-month follow-up. Contact Dermatitis. 2013;68(3):169-74.

124. Richards HL, Fortune DG, Main CJ, Griffiths CEM. Stigmatization and psoriasis. Br J Dermatol. 2003;149(1):209_ 11.

125. Picardi A, Abeni D, Renzi C, Braga M, Puddu P, Pasquini P. Increased psychiatric morbidity in female outpatients with skin lesions on visible parts of the body. Acta Derm Venereol. 2001;81(6):410-4.

126. Pereira MG, Brito L, Smith T. Dyadic adjustment, family coping, body image, quality of life and psychological morbidity in patients with psoriasis and their partners. Int J Behav Med. 2012;19(3):260-9. 
127. Eghlileb AM, Davies EEG, Finlay AY. Psoriasis has a major secondary impact on the lives of family members and partners. Br J Dermatol. 2007;156(6):1245-50.

128. Sampogna F, Gisondi P, Tabolli S, Abeni D, and the IDI Multipurpose Psoriasis Research on Vital Experiences investigators. Impairment of sexual life in patients with psoriasis. Dermatology. 2007;214(2):144-50.

129. Berger K, Ehlken B, Kugland B, Augustin M. Cost-of-illness in patients with moderate and severe chronic psoriasis vulgaris in Germany. J Dtsch Dermatol Ges. 2005;3(7):511-8.

130. Gaikwad R, Deshpande S, Raje S, Dhamdhere DV, Ghate MR. Evaluation of functional impairment in psoriasis. Indian J Dermatol Venereol Leprol. 2006;72(1):37-40.

131. Sohn S, Schoeffski O, Prinz J, Reich K, Schubert E, Waldorf $K$ et al. Cost of moderate to severe plaque psoriasis in Germany: a multicenter cost-of-illness study. Dermatology. 2006;212(2):137-44.

132. Fowler JF, Duh MS, Rovba L, Buteau S, Pinheiro L, Lobo F et al. The impact of psoriasis on health care costs and patient work loss. J Am Acad Dermatol. 2008;59(5):772-80.

133. Javitz HS, Ward MM, Farber E, Nail L, Vallow SG. The direct cost of care for psoriasis and psoriatic arthritis in the United States. J Am Acad Dermatol. 2002;46(6):850-60.

134. Bhutani T, Wong JW, Bebo BF, Armstrong AW. Access to health care in patients with psoriasis and psoriatic arthritis: data from National Psoriasis Foundation survey panels. JAMA Dermatol. 2013;149(6):717-21.

135. Navarini AA, Laffitte E, Conrad C, Piffaretti P, Brock E, Ruckdaeschel S et al. Estimation of cost-of-illness in patients with psoriasis in Switzerland. Swiss Med Wkly. 2010;140(5-6):85-91.

136. Mattei PL, Corey KC, Kimball AB. Psoriasis Area Severity Index (PASI) and the Dermatology Life Quality Index (DLQI): the correlation between disease severity and psychological burden in patients treated with biological therapies. J Eur Acad Dermatol Venereol. 2014;28(3):333-7.

137. Armstrong AW, Schupp C, Wu J, Bebo B. Quality of life and work productivity impairment among psoriasis patients: findings from the National Psoriasis Foundation survey data 2003-2011. PloS One. 2012;7(12):e52935.

138. Levy AR, Davie AM, Brazier NC, Jivraj F, Albrecht LE, Gratton D et al. Economic burden of moderate to severe plaque psoriasis in Canada. Int J Dermatol. 2012;51(12):1432-40.

139. Blome C, Augustin M, Behechtnejad J, Rustenbach SJ. Dimensions of patient needs in dermatology: subscales of the patient benefit index. Arch Dermatol Res. 2011;303(1):11-17.

140. Quality of life and cost of illness in patients with psoriasis in Malaysia: a multicenter study.

141. Norlin JM, Steen Carlsson K, Persson U, Schmitt-Egenolf M. Analysis of three outcome measures in moderate to severe psoriasis: a registry-based study of 2450 patients. Br J Dermatol. 2012;166(4):797-802.

142. Augustin $M$. Identifying patients at risk. In: Kimball AB, Linder M, Itin P, Jemec GB, editors. Dermatological diseases and cumulative life course impairment. Basel: Karger Verlag; 2013:74-81.

143. Renzi C, Picardi A, Abeni D, Agostini E, Baliva G, Pasquini P et al. Association of dissatisfaction with care and psychiatric morbidity with poor treatment compliance. Arch Dermatol. 2002;138(3):337-42.

144. Fortune DG, Richards HL, Kirby B, Bowcock S, Main CJ, Griffiths CEM. A cognitive-behavioural symptom management programme as an adjunct in psoriasis therapy. Br J Dermatol. 2002;146(3):458-65.

145. Jankowiak B, Krajewska-Kulak E, Van Damme-Ostapowicz K, Wronska I, Lukaszuk C, Niczyporuk W et al. The need for health education among patients with psoriasis. Dermatol Nurs. 2004;16(5):439-44.

146. Larsen MH, Krogstad AL, Aas E, Moum T, Wahl AK. A telephone-based motivational interviewing intervention has positive effects on psoriasis severity and self-management: a randomized controlled trial. Br J Dermatol. 2014;171(6):1458-69.

147. Pagliarello C, Calza A, Armani E, DI Pietro C, Tabolli S. Effectiveness of an empowerment-based intervention for psoriasis among patients attending a medical spa. Eur J Dermatol. 2011;21(1):62-6.

148. Mansouri B, Patel M, Menter A. Biological therapies for psoriasis. Expert Opin Biol Ther. 2013;13(12):1715-30.

149. 19th WHO Model Essential Medicines List [Internet]. Geneva: World Health Organization; 2015 (http://www. who.int/entity/selection_medicines/committees/expert/20/EML_2015_FINAL_amended_AUG2015.pdf?ua=1, accessed 17 October 2015). 
150. Nast A, Boehncke W-H, Mrowietz U, Ockenfels H-M, Philipp S, Reich K et al., and the Deutsche Dermatologische Gesellschaft (DDG), Berufsverband Deutscher Dermatologen (BVDD). S3 - Guidelines on the treatment of psoriasis vulgaris (English version). Update. J Dtsch Dermatol Ges. 2012;10 (Suppl. 2):S1-S95.

151. Pathirana D, Ormerod AD, Saiag P, Smith C, Spuls PI, Nast A et al. European S3-guidelines on the systemic treatment of psoriasis vulgaris. J Eur Acad Dermatol Venereol. (Suppl. 2):S1-S95.

152. National Institute for Health and Care Excellence. Psoriasis: assessment and management. NICE guidelines [CG153] [Internet]. London; 2012 (https://www.nice.org.uk/guidance/cg153/resources/psoriasis-assessment-andmanagement-35109629621701, accessed 17 October 2015).

153. Mease PJ, Gladman DD, Helliwell P, Khraishi MM, Fuiman J, Bananis E et al. Comparative performance of psoriatic arthritis screening tools in patients with psoriasis in European/North American dermatology clinics. J Am Acad Dermatol. 2014;71(4):649-55.

154. Romero-Talamás H, Aminian A, Corcelles R, Fernandez AP, Schauer PR, Brethauer S. Psoriasis improvement after bariatric surgery. Surg Obes Relat Dis. 2014;10(6):1155-9.

155. Farias MM, Achurra P, Boza C, Vega A, de la Cruz C. Psoriasis following bariatric surgery: clinical evolution and impact on quality of life on 10 patients. Obes Surg. 2012;22(6):877-80.

156. Hossler EW, Wood GC, Still CD, Mowad CM, Maroon MS. The effect of weight loss surgery on the severity of psoriasis. Br J Dermatol. 2013;168(3):660-1.

157. Debbaneh M, Millsop JW, Bhatia BK, Koo J, Liao W. Diet and psoriasis, part I: Impact of weight loss interventions. J Am Acad Dermatol. 2014;71(1):133-40.

158. Gisondi P, Del Giglio M, Di Francesco V, Zamboni M, Girolomoni G. Weight loss improves the response of obese patients with moderate-to-severe chronic plaque psoriasis to low-dose cyclosporine therapy: a randomized, controlled, investigator-blinded clinical trial. Am J Clin Nutr. 2008;88(5):1242-7.

159. Thorleifsdottir RH, Sigurdardottir SL, Sigurgeirsson B, Olafsson JH, Sigurdsson MI, Petersen H et al. Improvement of psoriasis after tonsillectomy is associated with a decrease in the frequency of circulating $T$ cells that recognize streptococcal determinants and homologous skin determinants. J Immunol. 2012;188(10):5160-5.

160. Skudutyte-Rysstad R, Slevolden EM, Hansen BF, Sandvik L, Preus HR. Association between moderate to severe psoriasis and periodontitis in a Scandinavian population. BMC Oral Health. 2014;14:139.

161. Remröd C, Sjöström K, Svensson Å. Subjective stress reactivity in psoriasis: a cross sectional study of associated psychological traits. BMC Dermatol. 2015;15:6.

162. Augustin M, Holland B, Dartsch D, Langenbruch A, Radtke MA. Adherence in the treatment of psoriasis: a systematic review. Dermatology. 2011;222(4):363-74.

163. Thorneloe RJ, Bundy C, Griffiths CEM, Ashcroft DM, Cordingley L. Adherence to medication in patients with psoriasis: a systematic literature review. Br J Dermatol. 2013;168(1):20-31.

164. World Health Statistics 2015 [Internet]. Geneva: World Health Organization; 2015 (http://apps. who.int/iris/ bitstream/10665/170250/1/9789240694439_eng.pdf?ua=1\&ua=1, accessed 12 August 2015).

165. WHO Global health expenditure atlas. Geneva: World Health Organization; 2014.

166. Abdulghani M, Al Sheik A, Alkhawajah M, Ammoury A, Behrens F, Benchikhi $\mathrm{H}$ et al. Management of psoriasis in Africa and the Middle East: a review of current opinion, practice and opportunities for improvement. J Int Med Res. 2011;39(5):1573-88.

167. Augustin M, Alvaro-Gracia JM, Bagot M, Hillmann O, van de Kerkhof PCM, Kobelt G et al. A framework for improving the quality of care for people with psoriasis. J Eur Acad Dermatol Venereol. 2012;26(Suppl. 4):1-16.

168. Pearce DJ, Thomas CG, Fleischer AB, Feldman SR. The cost of psoriasis therapies: considerations for therapy selection. Dermatol Nurs Dermatol Nurses Assoc. 2004;16(5):421-8, 432.

169. D'Souza LS, Payette MJ. Estimated cost efficacy of systemic treatments that are approved by the US Food and Drug Administration for the treatment of moderate to severe psoriasis. J Am Acad Dermatol. 2015;72(4):589-98. 
170. Beyer V, Wolverton SE. Recent trends in systemic psoriasis treatment costs. Arch Dermatol. 2010;146(1):46-54.

171. Griffiths CEM, Taylor H, Collins SI, Hobson JE, Collier PA, Chalmers RJG et al. The impact of psoriasis guidelines on appropriateness of referral from primary to secondary care: a randomized controlled trial. Br J Dermatol. 2006;155(2):393-400.

172. Augustin M, Radtke M, Eissing L, Enk A, Luger T et al. The German National Program on Psoriasis Care 20052015: results and experiences. Arch Dermatol Res. In press.

173. Feuerhahn J, Blome C, Radtke M, Augustin M. Validation of the patient benefit index for the assessment of patient-relevant benefit in the treatment of psoriasis. Arch Dermatol Res. 2012;304(6):433-41.

174. WHO global strategy on people-centred and integrated health services: interim report [Internet]. Geneva: World Health Organization; 2015 (http://apps.who.int/iris/bitstream/10665/155002/1/WHO_HIS_SDS_2015.6_eng. pdf?ua=1\&ua=1, accessed 27 August 2015).

175. Implementation tools. Package of Essential Noncommunicable (PEN) disease interventions for primary health care in low-resource settings. Geneva: World Health Organization; 2013.

176. Raboobee N, Aboobaker J, Jordaan HF, Sinclair W, Smith JM, Todd G et al., and the Working Group of the Dermatological Society of South Africa. Guideline on the management of psoriasis in South Africa. S Afr Med J. 2010;100(4 Pt 2):257-82.

177. The International Foundation for Dermatology (IFD). The Regional Dermatology Training Centre, Tanzania[Internet]. (http://www.ifd.org/the-regional-dermatology-training-centre,-tanzania, accessed 1 December 2015). 
Worlo heath

Organization

\section{World Health Organization}

20. Avenue Appia

1211 Geneva 27

$$
\text { Switzerland }
$$

Tel. +41227912111

Fax: +41227913111

www.who.int

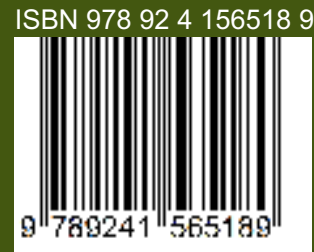

